\title{
Grammaticalization vs. Reanalysis: a Semantic- Pragmatic Account of Functional Change in Grammar
}

\author{
Ulrich Detges und Richard Waltereit
}

\begin{abstract}
Most current theorizing conceives of grammaticalization (and reanalysis) in purely structural-descriptive terms, according to Lehmann's (1995) parameters. But these leave fundamental questions unanswered: what do speakers/hearers actually do when they "grammaticalize"/"reanalyze" a linguistic item? We will show reanalysis to be essentially a hearer-based procedure. Listeners aim at understanding what speakers say. Grammaticalization, on the other hand, is a speaker-based phenomenon: Speakers invent expressive discourse techniques in order to pay tribute to basic communicative needs such as "to tell the truth", "to be relevant"; as a consequence of routinization, these techniques will lose their salience and their relics end up by becoming part of the grammar. Like any type of change, grammaticalization is ratified by reanalyses on the part of listeners. In a trivial sense, lexical elements are reanalyzed as grammatical ones. Only in this sense are reanalysis and grammaticalization "inseparable twins".
\end{abstract}

\section{The relation of grammaticalization and reanalysis: a controversial issue}

Rea nalysis is a central notion in diachronic syntax, in generative as well as in functional research. While there seems to be a broad consensus on its centrality and an intuitive understanding of what reanalysis is, its precise nature and delimitation are far from clear. Particularly controversial seems to be its relation to grammaticalization. Heine, Claudi and Hünnemeyer (1991: 219) claim that "grammaticalization and reanalysis appear to be inseparable twins". Similarly, Hopper and Traugott (1993: 32) maintain that every grammaticalization is accompanied by a reanalysis: "Unquestionably, reanalysis is the most important meclhanism for grammaticalization, as for all change". However, they insist on the theoretical independence of the two processes: "It is best, then, to regard grannmaticalization as a subset of changes involved in reanalysis, rather than to identify the two" (Hopper and Traugott 1993: 50). According to Haspelmath (19918: 344), "[t]he main mechanism of syntactic change is grammaticalization". He makes a strong point in claiming that neither of the two processes is 
necessarily involved in the other and that they are "disjoint classes of phenomena" (Haspelmath 1998: 315). Two of his statements, both in Haspelmath (1998: 318-27), are of special interest for our further argumentation. He claims a) that grammaticalization is a unidirectional and irreversible process, whereas reanalysis is typically bi-directional and, at least in principle, reversible, and b) that grammaticalization is a gradual phenomenon, whereas reanalysis typically is abrupt.

In generative syntax, on the other hand, reanalysis is typically considered the key mechanism of grammatical change (Roberts 1993a: 158. Battye and Roberts 1995, van Kemenade and Vincent 1997: 2), thereby denying grammaticalization a theoretically relevant role in diachronic syntax (Roberts 1993b). Similarly, but not from a generative point of view, Harris and Campbell (1995: 20) do not consider grammaticalization a type of grammatical change in its own right.

In our view, the reason for these problems of delimitation is that in most current theorizing, reanalysis and grammaticalization are discussed in purely structural terms. Our contribution is intended to clarify the issue from a cognitive-pragmatic viewpoint. We want to argue that reanalysis and grammaticalization arise as a consequence of basic needs of communication, which can be identified as listeners' strategies in the case of reanalysis and as speakers' strategies in the case of grammaticalization.

To begin with, two simple examples of reanalysis and grammaticalization will be discussed in order to have the apparent facts at hand.

\subsection{Reanalysis: rebracketing and categorial relabeling}

The Spanish se middle voice, attested from early Old Spanish onwards, was reanalyzed as an impersonal construction in the 15th century (cf. Lapesa 2000: 808-17). The two readings which mark the beginning and the endpoint of that change are set out in the fictive example (1a/b). ${ }^{1}$

a. Before reanalysis: se as clitic middle marker

se vende cerveza $_{i}$ en el patio

[MM-sell $]_{\mathrm{VP}}$ beer $_{\text {isums }}$ in the courtyard

'Beer is sold in the courtyard'

1 The following abbreviations will be used in this article: $i, j=$ referential indices, $V P=$ verb phrase, sUBJ $=$ subject, $N P=$ noun phrase, $S=$ singular, $\mathrm{P}=$ plural, $\mathrm{ACC}=\mathrm{ac}-$ cusative, $\quad$ NEG $=$ negation, $\quad M M=$ middle marker, $\quad$ PRES $=$ present, $\quad$ ADV $=$ adverb, $\mathrm{DO}=$ direct object, $\mathrm{F}=$ French, $\mathrm{OF}=$ Old French, $\mathrm{E}=$ English, $\mathrm{C}=$ Catalan, $\mathrm{R}=\mathrm{Ro}$ mansh, $\mathrm{L}=$ Latin, $/ \backslash=$ discontinuous constituent 
b. After reanalysis: se as impersonal subject clitic

$\mathrm{se}_{i} \quad$ vende $_{i}$ cerveza en el patio

[one $_{i \text { sca }}$-sells beer $\left._{\text {ix }}\right]_{v p}$ in the courtyard

'(Some)one sells beer in the courtyard'

Before reanalysis, the sequence se vende cerveza en el patio is in the middle voice and means 'beer is sold in the courtyard'. After reanalysis, se is interpreted as the clitic subject of an impersonal construction which means 'someone sells beer in the courtyard. When considering the process of reanalysis itself in more detail, we will however see that there are intermediate steps between (1a) and (1b). In the entire process, the phonological shape of the construction does not change; what does change, however, is the syntactic structure. Before reanalysis, the verb phrase is made up of the middle marker se and the verb vende; after reanalysis, se is the clitic subject of the construction, and the verb phrase is made up of the verb vende and the new direct object cerveza. This rebracketing process, typical for reanalysis, is illustrated again in (2a). It follows the more abstract pattern set out in (2b).

a. $[\text { se-vende }]_{\mathrm{VP}}[\text { cerveza }]_{\mathrm{NP}}>\left[\text { se }_{i}-\text {-vende }_{i}[\text { cerveza }]_{\mathrm{NP}}\right]_{\mathrm{VP}}$

b. $[\mathrm{X}$ Y $][\mathrm{Z}]>[\mathrm{X}$ Y $[\mathrm{Z}]]$

This means that the constituent structure is rebracketed. At the same time, the element se changes its category: the middle marker becomes a subject pronoun. These two features - rebracketing and category relabeling - are changes that affect the internal structure of a construction, but not its surface form. This is in conformity with the classical definition of reanalysis put forward by Langacker (1977: 58), who defined reanalysis as "change in the structure of an expression or class of expressions that does not involve any immediate or intrinsic modification of its surface manifestation".

\subsection{Grammaticalization: from lexical (less grammatical) to (more)} grammatical status

As a standard example of grammaticalization, consider the French negation ne ... pas. A lexical item, the Latin full noun passus 'step', has turned into a grammatical item, the Modern French negation marker pas.

a. Before grammaticalization: Latin

non vado passum

NEG go:1sG step:ACC

I don't go a step' 
b. After grammaticalization: Modern French

je ne vais pas

I NEG go:1SG NEG

I don't go'

The seemingly unrelated processes of grammaticalization and reanalysis prove on closer inspection to be somehow interconnected, as one considers how the syntax of the entire construction changes in the grammaticalization process.

$$
\text { non }_{\mathrm{XEG}}[\text { vado passum }]_{\mathrm{vP}}>\left[\text { ne } /_{\mathrm{VEG}}\left[\text { vais }_{\mathrm{VP}}\right] \backslash \text { pas }_{\mathrm{VEG}}\right]
$$

As shown in (4), the constituency relations in the grammaticalization example follow a rebracketing pattern similar to the one described in ( $2 b)$, and, of course. the full noun passus undergoes category relabeling. Hence, grammaticalization and reanalysis seem to share relevant structural properties and it might appear that grammaticalization is just an instance of reanalysis (cf. Harris/Campbell 1995, Roberts 1993a, Battye/Roberts 1995, van Kemenade/Vincent 1997). In the remainder of this article, we will show that such an account would fail to capture the peculiarities that distinguish grammaticalization from reanalysis. Our argumentation will be based on the following three claims, for which both theoretical and empirical support will be provided.

(5) a. Reanalysis arises through language use, not as a consequence of system requirements. The old and the new syntactic structure are not linked by systematic syntactic relations (such as voice, movement etc.). Rather, the relation between the two structures is based on their use in the same type of situation. This will be explained in section 2 .

b. Reanalysis is not primarily syntactic but semantic. Reanalyses are triggered by certain types of semantic change, above all by metonymy, but also by taxonomic change. As we will set forth in section 3 , re-bracketing and categorial re-labeling are only by-products of semantic change.

c. Grammaticalization is an instance of semantic change, as is reanalysis. The crucial difference between the two processes is that reanalysis is the result of a strategy of interpretation, i. e., it is listener-based. Grammaticalization, on the other hand, is the unintentional result of expressive discourse techniques, i. e., it is speaker-based. This claim will be substantiated in section 4 . 


\section{Is reanalysis non-directional? Two cognitive principles}

Reanalysis is usually thought of as non-directional in the sense that it has no inherent properties governing its direction of application (Heine and Reh 1984: 95. Harris and Campbell 1995: 88. Haspelmath 1998: 325-26). This view predicts that it should in principle be possible to find pairs of structural configurations where reanalyses in either direction are historically attested. As noted by Haspelmath (1998: 326), morphological reanalyses operating in opposite directions are not uncommon indeed (cf. also Langacker 1977: 65, 134-135). In (6). an article fuses with its nominal head and becomes part of the noun stem; in (7), on the other hand, a part of the noun stem is separated and turns into a definite article.

(6) French le chien 'the dog' > Seychelles Creole lisyen 'dog'

(7) Italian l'alicorno 'the unicorn' > Middle French la licorne 'the unicorn'

Judging from the results, this kind of change seems non-directional. But when examining these processes more carefully, it becomes clear that we are dealing with two fundamentally different types of reanalyses that only accidentally yield symmetric results. We want to argue that these two types of reanalyses are related to two different pragmatic strategies, which will be examined in detail in the following subsections.

\subsection{The principle of reference}

Example (6) is a change brought about in a situation of language contact and non-directed second language acquisition, typical of creolization (cf. Chaudenson 1992, Detges 2000). The sound chains French le chien and Seychelles Creole lisyen are phonologically highly similar. The main difference resides in their respective morphological segmentation: le chien has two morphemes (the article and the noun itself), lisyen on the other hand consists of only one morpheme (it is a simple noun). The French NP has been reanalyzed as a simple noun in Seychelles Creole. Figure (8) illustrates our hypothesis on how this reanalysis has come about. In situations of non-directed second language acquisition, typical of early stages of creolization, learners, lacking metalinguistic and grammatical information about the target language, have to rely on what they can actually see and hear. Thus, they can hear the sound chain le chien and they can see what is apparently meant - a dog. However, they have no access to the underlying French morphological structure. Under these conditions, the only way to understand the utterance is to match it with what is apparently meant in the situation, and to construe a simple morphology according to the interpretation (cf. Detges 2000: 147-50). 


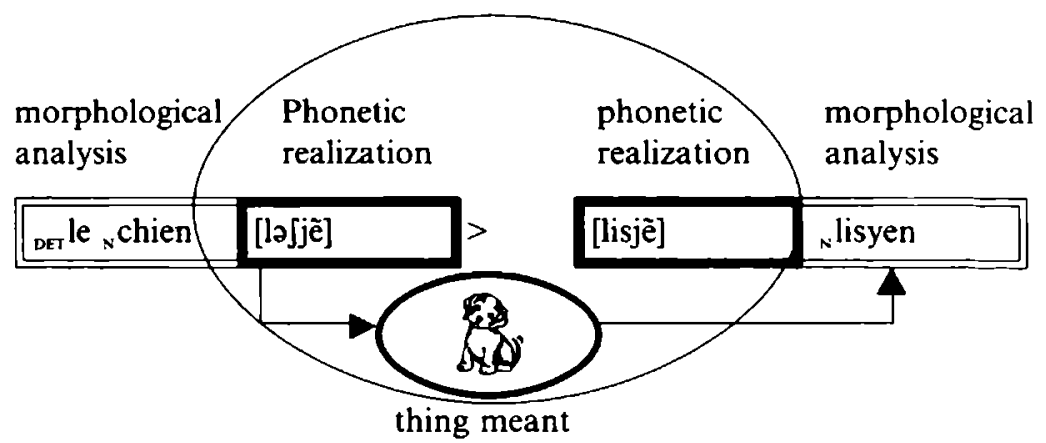

We want to term the procedure illustrated by fig. (8) the principle of reference: ${ }^{2}$

\section{Principle of reference:}

Assume that the conventional semantics of the sound chain you hear corresponds to what seems to be meant in the situation.

The principle of reference is a strategy of understanding. It is grounded in the basic semiotic assumption that forms of language normally mean what they refer to. A competent listener, who is able to decode the meaning of the sound chain, seeks some referent that matches the semantic content of the sound chain. A non-competent listener, e.g. an acquirer in non-directed second language acquisition, must proceed the other way round: he does not know what the conventional meaning of the sound chain is, but he sees what it is referring to. This is where the principle of reference comes into play. The listener now can reasonably suppose that the meaning of the sound chain corresponds to the type of referent it is used to refer to. The principle of reference often decreases morphological complexity, as in (6). The maximally simple analysis is to suppose that the sound chain le chien as a unit of form represents a single unit of content, namely the meaning ' $\mathrm{dog}^{3}{ }^{3}$ As we will argue later, the principle of reference seems to be the most important principle in reanalysis.

2 The term "reference" is used here in a very general understanding, in that it denotes any kind of extralinguistic communicative intention. It encompasses not only reference to individual entities, but also illocutionary acts.

3 What level of categorization is relevant for the listener's interpretation depends of course on the situation. In the unmarked case the listener will choose the basic level interpretation DOG, in other types of situation he might select the superordinate level categorization MAMMAL or, on the contrary, a subordinate level categorization like BADGER DOG or DACHSHUND. The principle of reference makes no prediction about levels of categorial abstraction. 
The principle of reference is not restricted to language contact. For example, compounds are often reanalyzed as simple words within the same language (cf. Harnisch 1999):

$$
\begin{aligned}
& \text { a. }\left[\operatorname{cup}_{\mathrm{s}} \text { board }\right]_{\mathrm{N}} / \mathrm{k} \wedge \mathrm{pb} \text { :d/> cupboard } \mathrm{d}_{\mathrm{N}} / \mathrm{k} \wedge \text { bbəd/ } \\
& \text { b. [sheep herd, }]_{\mathrm{v}}>\text { shepherd } \\
& \text { c. }\left[\text { well }_{A \mid>} \text { come }\right]_{\mathrm{v}}>\text { welcome }
\end{aligned}
$$

Reference to some entity by means of a two-element compound requires a three-way categorization of that referent (Gévaudan 1999). For example, in order to identify some referent as a $\left[\text { cup }_{\mathrm{v}} \text { hoard }\right]_{\mathrm{N}}$, the listener has to recognize the BOARD, the CUPS, and some salient relation between the BOARD and the CUPS that makes the set of both a single referent. Compounds are therefore rather complex types of reference for both speaker and listener. A speaker who wants to avoid this complexity may choose a simple word instead. The listener, however, cannot avoid this complexity in principle, given that he wants to understand what the speaker says. But if he hears the same type of referent being referred to by the same compound of ten enough, i. e., if both the type of referent and the form that refers to it are sufficiently entrenched as a cognitive category and a linguistic unit, respectively (Langacker 1987: 59-60), he may reanalyze the compound as a materially identical simple word. This reanalysis is guided by the principle of reference, as the type of the referent being referred to becomes the meaning of the sound chain cupboard, thereby replacing the combination of the meanings of cup and board in the compound interpretation. This process creates a new lexical unit cupboard that is stored and accessed holistically, not synthetically (as a compound would be). This corresponds to what Lehmann $(1989 ; 1999)$ has called lexicalization. The changes in form that the former compounds cupboard, shepherd, and welcome have undergone later are morphophonogical reflexes of the loss of the morpheme boundary. It is important to stress that this type of language-internal reanalysis is highly favored by high frequency of the complex structure in question.

Some recent studies have discussed the reanalysis of the French postverbal 3sG subject pronoun $i l$ in complex inversion constructions as an interrogative particle in some varieties of that language, including Québécois (Harris and Campbell 1995: 66, Haspelmath 1998, Waltereit 1999). This reanalysis is to be imputed to the principle of reference.

4 A newly reanalyzed simple word may very well remain formally transparent for a long while without being semantically compositional. For example, in contemporary English the word graveyard can still easily be decomposed as "a yard full of graves". Nonetheless, competent speakers to English normally do not proceed this way, but match the word as a whole with the type of referent to which it usually refers. 

a. Pierre ${ }_{\mathrm{i}}$ vient-ili ${ }_{\mathrm{i}}$ ?
Pierre come:3sg:Masc
'Does Pierre come?'
b. Marie vient-elle?
Marie come:3sG-3SG:FEM
a. Pierre vient- $\mathrm{ti}_{\mathrm{PTC}}$ ?
Pierre come:3sG-QUESTION
'Does Pierre come?'
b. Marie vient- $\mathrm{i}_{\mathrm{PTC}}$ ?
Marie come:3sg-question
'Does Marie come?'

In $(11 \mathrm{a} / \mathrm{b})$, the pronouns elle and $i$ have a double function. They are anaphoric pronous of the subject Pierre and Marie, respectively, and at the same time they indirectly mark, by virtue of the word order their position indicates, interrogative sentence type. Note that the occurrence of the anaphoric pronoun is grammatically enforced by the choice of the interrogative sentence type in connection with a full NP subject. In this case, the pronoun does not instantiate a free choice of the speaker to refer back to some previous linguistic element, as would be the normal case with anaphors. Therefore the anaphoric force of elle and $i l$ is somewhat weak. The reanalysis consists in taking the masculine pronoun, which owes its position to word order requirements of the interrogative sentence, in connection with verb-final $-t$ as a morphematic marker of interrogative sentences. This becomes morphologically manifest in (12b), where the feminine subject, too, has $t i$ as an interrogative particle. $(12 \mathrm{a} / \mathrm{b})$ is clearly an instantiation of the principle of reference, as the postverbal il comes to be conventionally identified with what is meant in the situation, i. e., interrogative illocution, thereby losing its anaphoric function altogether.

\subsection{The principle of transparency}

The second, less important principle in reanalysis leads to an increase in morphological or syntactic complexity. This will be illustrated by commenting on example (7), Italian l'alicorno 'the unicorn' > French la licorne 'the unicorn'. This borrowing process took place in the 14th century (see von Wartburg 1922 s. v. "Unicornis" for details). ${ }^{5}$

5 Langacker (1977: 134-5) discusses a number of reanalyses in the history of F unicorne, among them the agglutination of an indefinite article in unicorne $>$ une nicorne. Langacker's sketch of the history of unicorne is not grounded on positive historical evidence but on plausibility assumptions. But the putative step unicorne $>$ une nicorne is actually historically implausible because in that period of Old French the feminine 
In order to understand the opaque sound chain l'alicorno (consisting of an elided definite article and a simple noun), the French-speaking listener matches it with French NPs, as la liaison 'the binding', la liesse 'the gaiety', la ligne 'the line', and he parses it using a morphological analysis which is analogous to other expressions of his language. As a result, the initial $a$ of the noun alicorno is reanalyzed as part of the French feminine definite article $l a{ }^{6}$ This is illustrated in (13).

(13) Italian

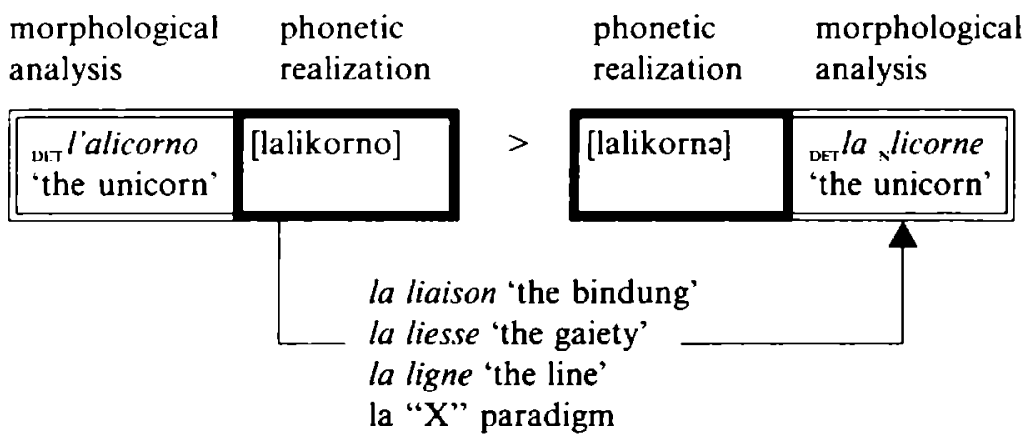

The strategy underlying this operation is set out in (14).

\section{Principle of transparency:}

Match the sound chain you hear with other sound chains of the language that you already know.

The principle of transparency (which has nothing to do with Lightfoot's 1979 transparency principle), is grounded in basic semiotic assumptions. Unlike the principle of reference, these assumptions do not concern the relation of meaning and reference, but the relation of form and meaning. The inferencing which underlies the principle of transparency supposes that identical functions should be expressed by identical forms and vice versa. As the listener detects in the sound chain l'alicorno the sequence $l a$, he reckons by analogy that this form should mean the same thing here as elsewhere in the language. In Natural Morphology, this strategy has been referred to under the label of "uniformity"

indefinite article une was pronounced [ynכ] so that the sound sequences corresponding to unicorne and une nicorne were not sufficiently similar phonetically.

6 That the resulting French noun is licorne and not licorno is due to morphophonological adaptation to the target language, a process that is very frequent in borrowing, and independent of the reanalysis under discussion. 
as a preference principle of morphological structure (cf. Mayerthaler 1981: 34-36).

Just as the principle of reference, the principle of transparency is a strategy for understanding, but in a completely different way. It is highly active in folk etymology:
a. Portuguese vagabundo 'vagabond' > vagamundo
b. Latin capitolium 'Capitol Hill' > Italian campidoglio

The folk-etymological change in (15a) is a transparency-based reanalysis. following an analogy to vaguear 'to stroll around' and mundo 'world'. Italian campidoglio is also due to a transparency-based reanalysis, by analogy to campo 'field' and olio 'oil'. Lehmann (1995b: 1262) seems to suggest that analogy is the standard case in reanalysis, but on closer inspection this hypothesis turns out to be ill-founded. Our examples $(15 \mathrm{a} / \mathrm{b})$ show that the principle of transparency is constrained by the principle of reference. A vagabond is actually someone who "strolls around the world", and the Capitol Hill in Rome was actually covered with olive trees. This means that in a reanalysis brought about by the principle of transparency the ability of the string to refer to the same type of referent has been preserved. Hence, the principle of transparency allows only reanalyses that conform to the principle of reference; therefore, it is the less important one.

The subsidiary nature of the principle of transparency can also be shown from a different perspective. The principle of reference is a general semiotic principle concerning the relation between meaning and reference. It does not per se require mastery of the language in question (on the contrary: as shown, it may help to compensate for insufficient proficiency, as in non-directed second language acquisition). The successful application of the principle of transparency, however, always implies knowledge of the relevant language, because it makes crucial reference to the relation of form and content in that language. Given that the principle of transparency is more specific than the principle of reference, it is therefore also expected to be more restricted in scope. The principle of reference is the "default" principle in reanalysis. The Spanish impersonal construction (1b) is a good example of a transparency-based reanalysis. In the 15 th century, the middle construction se vende cerveza en el patio 'beer is being sold in the courtyard' underwent a semantic change towards the impersonal meaning 'one sells beer in the courtyard' which it still has today. We will return to a detailed description of this meaning change later on (section

7 Harris and Campbell (1995: 70-1) rightly state that opacity is not a prerequisite to reanalysis. However, there is a clearly definable subset of reanalyses that do require opacity: reanalyses arising in language contact. Furthermore, transparency-based reanalyses do not require opacity in principle, but are nevertheless closely related to it as they enhance transparency in the relation of form and function. 
3.1.). In a second (and logically independent) step, a syntactic reanalysis conferred to the sequence se vende cerveza en el patio (16a) an additional syntactic structure, namely (16b), which today is considered non-standard:

$$
\begin{aligned}
& \text { a. se vende, cerveza, en el patio }
\end{aligned}
$$

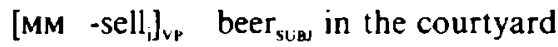

$$
\begin{aligned}
& \text { b. } s_{i} \text { vende }_{i} \text { cerveza en el patio } \\
& \text { [one } \left._{\text {isus }}-\text { sells }_{i} \text { beer }_{\text {Dod }}\right]_{i p} \text { in the courtyard }
\end{aligned}
$$

We would like to claim that structure (16b) has arisen from structure (16a) through a transparency-based reanalysis. Impersonal constructions like (16a/b) have a single argument (cerveza) in the postverbal focal position, which in structure (16a) is analyzed as a subject and in (16b) as a direct object. In post-medieval Spanish, syntactic processing of single arguments in postverbal, focal position like cerveza is exposed to two conflicting coding principles:
a. Single arguments are subjects.
b. Focal arguments are non-subjects.

Analysis (16a) follows principle (17a), analysis (16b) satisfies principle (17b). The change from (16a) to (16b) also complies with the principle of reference. The listener who understands $s e_{i}$-vende ${ }_{i}$ cerveza refers to the same state of affairs as the speaker who utters se vende cerveza $_{i}$.

\subsection{Is reanalysis triggered by system requirements or by language use?}

The principle of reference predicts that the sound chain designates the same state of affairs before and after the reanalysis. It is this identity of reference, not a syntactic operation in the strict sense, that accounts for the relation between the old and the new constituent structure, as claimed in (5a). For example, there is no systematic syntactic relation between them, such as movement or voice. This claim partly contradicts generative theories of reanalysis, which usually invoke simplification of the underlying syntactic structure as the motivation for reanalysis (cf. Lightfoot 1979, Roberts 1993a, Roberts 1993b: 228). . True, also

8 The role of these coding principles is especially important for Spanish where word order has been relatively free from the Middle Ages onwards. However, Bossong 1984 shows that by the 16 th century (i. e. the time the syntactic reanalysis towards $(1 \mathrm{~b}) /(16 \mathrm{~b})$ occurred) the preferred word order shifted from verb-subject to subject-verb.

9 Note however that Lightfoot (1979: 141-9) acknowledges that there is no systematic (formal) syntactic relation between the structures before and after reanalysis. 
according to the view defended here, reanalysis may result in a simplification of the constituent structure, and this is even predicted to be likely as a consequence of an instantiation of the principle of reference. But, importantly, we do not consider the syntactic phenomenon of structural complexity as such to be a motivation for reanalysis. The important thing, rather, is that different semantic analyses with concomitant different syntactic and/or morphological structures of one and the same surface string are plausible alternatives of interpretation in the same utterance situation. ${ }^{10}$ This may, but need not, result in a simplification of the constituent structure (see (10) for a simplification, (15) for an increase in complexity). Our examples of reanalyses which are based on the principle of reference suggest that reanalysis is in general economy-driven. It facilitates language processing. Later, however, we will discuss, in connection with grammaticalization, reference-based reanalyses that are not economy-driven and that do not result in structure simplification. Furthermore, reanalyses based on the principle of transparency will in many cases lead to an increase in structural complexity.

Another aspect of language use is frequency. In section 2.1. it has been pointed out that language-internal reanalyses such as (10b) sheep-herd $>$ shepherd require a context where the compound has been used to refer to the same type of referent several times. i. e., they require entrenchment of the type of referent as a cognitive category.

To sum up: We hope to have shown that reanalyses are not due to random misunderstandings, as the claim of non-directionality might suggest. They follow two clearly distinguishable listeners' strategies of understanding. To this extent, they are, in a weak sense, directional, even though they may in some cases yield symmetrically opposed results.

\subsection{A comparison with Langacker's (1977) typology of reanalysis}

At this point of the discussion, it may be useful to relate the two strategies of reanalysis presented here to Langacker's (1977) typology of reanalysis. Langacker distinguishes three subtypes of what he calls "resegmentation", i. e., the manipulation of morpheme boundaries: boundary loss, boundary shift and boundary creation. These types of restructuring can easily be dealt with in the framework suggested here:

10 In many previous accounts of reanalyses, including generative ones, it is tacitly assumed that the reanalyzed structure maintains its ability to refer to the same referent as before. However, the importance of this has, to our knowledge, never been recognized before. 
Boundary loss: A very common type of boundary loss seems to be the morphological integration of compounds, as in (10a-c). Boundary loss is the morphological reflex of a process whereby two semantic units, as cup and board, come to be integrated into one single unit, as cupboard. Boundary loss is therefore an instantiation of the principle of reference as it adapts the morphological structure to what is meant in the situation.

It is not completely impossible to find reanalyses based on the principle of transparency that result in boundary loss. A case in point might be German Junker 'landowner':

$$
\left.\left[[\text { Jung }]_{\wedge}[\text { herr }]_{\mathrm{N}}\right]_{\mathrm{S}} \text { 'young sir' > [Junker }\right]_{\times} \text {'landowner' }
$$

Conforming to the principle of reference, the compound has been reanalyzed as a simple word and the morpheme boundary has been eliminated. In this case, also the principle of transparency might have been at work, due to an accidental similarity of the phonetic string -er to the agentive suffix -er, as in Herrsch-er 'governor', Fahr-er 'driver'. Harnisch 1999 offers more examples that allow for a similar interpretation.

Boundary creation and boundary shift: As pointed out by Langacker, boundary creation and boundary shift are both much rarer than boundary loss. We want to argue that boundary creation and boundary shift follow the principle of transparency. The instantiations of the principle of transparency discussed above involve either boundary creation (19) or boundary shift (20).

a. $[\text { vagabundo }]_{N}>\left[[\text { vaga }]_{v}[\text { mundo }]_{N}\right]_{N}$

b. [capitolium $]_{N}>\left[\text { campi }_{N}\left[\mathrm{~d}\left[\text { oglio }_{N}\right]\right]\right]_{N}$

(20) $\left[[\text { se vende }]_{v p}\right.$ cerveza $\left.a_{N}\right]$ en el patio $>$ [se-vende [cerveza $\left.]_{N}\right]_{v p}$ en el patio

Reanalyses governed by the principle of transparency create boundaries in order to motivate parts of the sound chain, as in (19), or shift boundaries according to analogous models in the language, as in (20). Boundary creation seems to be particularly important in folk etymology. However, as we will argue in the section on grammaticalization, it is not impossible per se to create or shift boundaries on the basis of the sole principle of reference.

\section{Reanalysis as a semantic type of grammatical change}

\subsection{Semantic relations in listener-based grammatical change}

The principle of reference and the principle of transparency describe listeners' strategies of understanding. We have shown how the application of such strategies may result in a new structural segmentation of the sound chain. The 
set of these two simple cognitive-pragmatic principles is fairly comprehensive, i. e., they can be applied to examples of morphological as well as of syntactic change. However, an important issue still has not been tackled sufficiently. In (5b), we have claimed that reanalysis is semantically motivated. Yet we have not described the semantic relation between the old and the new structure. This is the concern of the present section.

We assume that there are three possible types of paradigmatic semantic relations between (lexical or grammatical) units of content (cf. Blank 1997, Gévaudan 1999). These relations exist in diachrony, but also in synchrony as the result of semantic change:

1. METAPHORIC RELATIONS: Metaphoric relations imply a perceived similarity between two relata, as in mouse 'small rodent'/"computer mouse' or $t o$ grasp 'to seize'/"to understand'.

2. Metonymic relations: Metonymy is a figure-ground shift in a frame of contiguous concepts (cf. Koch 1999). As an example, take Latin focus 'fireplace'/'fire'. Contiguity means that (at least) one unit of content is inferable from the other one by virtue of their belonging to routines of everyday experience. In the case of 'fireplace' and 'fire' this is evident because FIRE in a household usually requires a FIREPLACE, and, conversely, the primary use of the FIREPLACE is to make a FIRE. Both belong to a number of routines of everyday experience. Their mutual inferability enables figure-ground shifts to operate synchronically and to change the meaning of a lexical item diachronically:

Metonymy as a figure-ground shift: L focus 'fireplace' > 'fire'

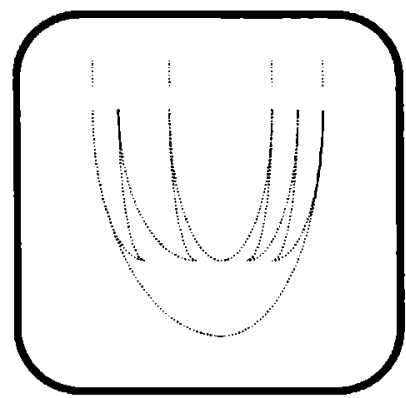

FIREPLACE

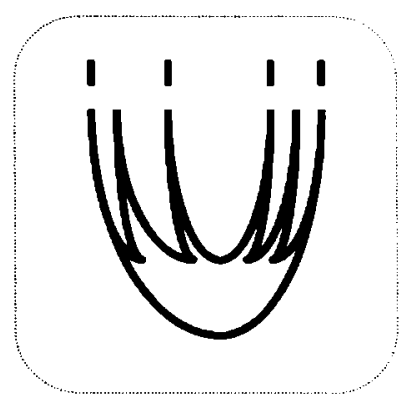

FIRE

Note that before the shift it is not the meaning of the word focus 'fireplace' that is ambiguous, but its use in certain frequent types of situations, like in incendamus focum! 'let's light the fireplace/the fire!' (Koch 1999: 155-6). The gist of fig. (21) can be schematized more abstractly, as in table (22): 


\begin{tabular}{|c|c|c|}
\hline lexical meaning & \multicolumn{2}{|c|}{$\begin{array}{l}\text { conceptual } \\
\text { contiguity }\end{array}$} \\
\hline Focus & FIREPLACE & FIRE \\
\hline 'fireplace' & 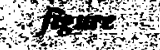 & ground \\
\hline 'fire' & ground & $4 x$ \\
\hline
\end{tabular}

In our understanding, also part-whole relations (synecdoche, meronymy) will be subsumed under metonymic relations.

3. TAXONOMIC RELATIONS: These include the classic semantic relations such as hyponymy, hyperonymy (e. g., sparrow is a hyponym of bird, just as bird is a hyperonym of sparrow) and antonymy (e.g. hot and cold are antonyms). They are "taxonomic" because they presuppose a previous conceptual hierarchy. A simple example of taxonomic change is Latin passer 'sparrow', which came to be its own hyperonym in Spanish pajaro 'small bird'.

We would like to argue that in reanalysis, the semantic relation between the old structure and the new structure is usually metonymic, or, possibly in a smaller number of cases, taxonomic, but never metaphoric. As explained in the examples, metonymic and taxonomic change is often triggered by high frequency and/or perceptual saliency of the relevant experience.

Consider examples (11), (12), repeated here for convenience:

Pierre $_{i}$ vient-il ${ }_{i}$ ?

'Does Pierre come?'

\author{
Pierre vient-ti prcs $_{\text {? }}$ ? \\ 'Does Pierre come?'
}

As discussed in 2.1., the anaphoric pronoun in (11), $i l$, is reanalyzed as an interrogative particle in (12). This is a contiguity-based change, similar to focus ,fireplace' > 'fire'. Albeit grammatically triggered by the interrogative sentence type, $i l$ in (11) is clearly still an anaphoric pronoun. Hence, it is the anaphoric function which in gestalt terms is the figure, while the interrogative function remains in the ground. Like in (21), the reanalysis consists in a reversal of figure and ground: 


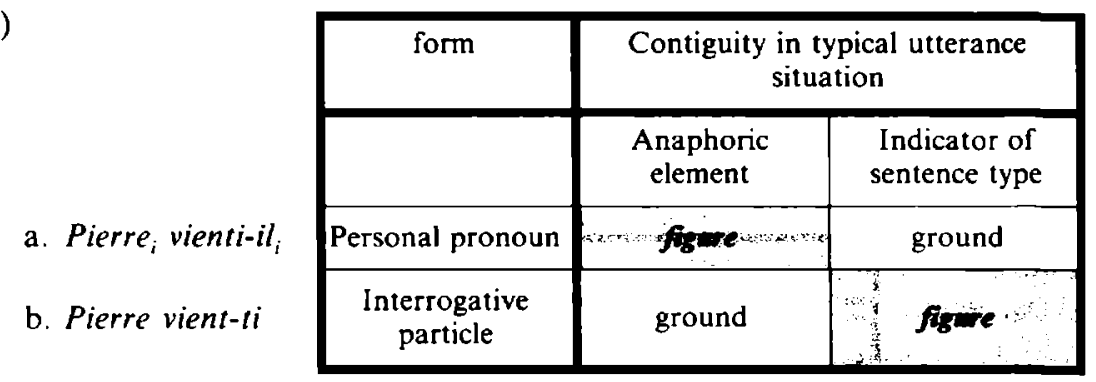

(23) is an example of metonymic change. Unlike the shift from 'fireplace' to 'fire', it is not based on a contiguity between concepts, but on a contiguity between a syntactic surface and a certain (i.e., interrogative) type of use.

Whereas in (23) syntactic change is the direct corollary of the metonymic reinterpretation, things are more complicated when the principle of transparency is involved. This is so because the latter follows the model of some rule of the language without necessarily instantiating a semantic change. However, even in such cases reanalysis is often motivated by a foregoing conceptual shift. A case in point is the history of the reanalysis of the Spanish middle construction (sketched in (1) and reproduced for convenience in (24)):

$$
\begin{aligned}
& \text { a. Before reanalysis: se as clitic middle marker } \\
& \text { se vende cerveza en el patio } \\
& {[\mathrm{MM} \text {-sell }]_{\mathrm{VP}} \text { beer }_{i \text { surs }} \text { in the courtyard }} \\
& \text { 'Beer is sold in the courtyard' }
\end{aligned}
$$

b. After reanalysis: se as impersonal subject clitic se $_{i} \quad$ vende $_{i}$ cerveza en el patio

[one $_{i s(B)}-$ sells $_{i}$ beer $_{\text {polvp }}$ in the courtyard

'(Some)one sells beer in the courtyard'

On a careful inspection it turns out that this syntactic reanalysis was preceded by a change of the middle construction's meaning. Even in modern Spanish, analysis (24a) continues both its old middle meaning and the new impersonal meaning." This means that before the syntactic reanalyis sketched in (24b) a meaning change has occurred in (24a). ${ }^{12}$ Again, this change is based on the

11 As Lapesa (2000: 815) remarks, in Modern Spanish the reflexive passive construction (24a) is clearly felt as active impersonal even if the verb grammatically agrees with the NP cerveza.

12 Koch (forthcoming) describes a similar case. With OF falir 'to be missing' a semantic change preceded syntactic restructuration, which turned this verb into an impersonal construction (cf. ModF il faut 'it is necessary'). 
principle of reference. In the middle voice interpretation, the construction (24a) refers to a state of affairs whose agent remains unmentioned. There is an agent, but it is out of focus. In its impersonal reading, the construction refers to an unspecific agent. The semantic difference is that in the first reading the agent is not mentioned (which neither implies nor excludes that the speaker knows the agent), while, in the second reading, the agent is not specific (i.e., the speaker does not know it). Clearly, there is a conceptual link between not being mentioned and not being specific, because in cooperative and efficient communication it is normally expected that unmentioned agents are either unknown or not worthwhile mentioning. hence unspecific. Not mentioning the agent is the figure of construction (24a)'s old meaning, while unspecificity is its background. That both readings (unspecificity and the status of not being mentioned) can have identical reference without having identical senses, is a strong cue for the contiguity relation between them. The figure-ground-shift in this metonymy is shown in (25).

a. middle

$$
s e_{\text {MID }} v \text { ende } \text { cerveza }_{i \mathrm{sUM}}
$$

b. active impersonal

$$
s e_{\text {Mo }} \text { vende }_{i} \text { cerveza }_{i \text { sum }}
$$

\begin{tabular}{|c|c|c|}
\hline meaning & \multicolumn{2}{|c|}{$\begin{array}{c}\text { Contiguity in typical utterance } \\
\text { situation }\end{array}$} \\
\hline $\begin{array}{c}\text { AGENT } \\
\text { UNMENTIONED } \\
\text { (These is an } \\
\text { agent, but it is } \\
\text { out of focus) }\end{array}$ & $\begin{array}{c}\text { AGENT NOT } \\
\text { SPECIFIC } \\
\text { (no particular } \\
\text { agent worth- } \\
\text { while mention } \\
\text { ing) }\end{array}$ \\
\hline NP is V-ed & $\begin{array}{c}\text { ground } \\
\text { (Some)one } \\
\text { Vs NP }\end{array}$ & ground \\
\hline
\end{tabular}

The contiguity analysis implies that each of the meanings is inferable from the other in either structure; they differ only in what is highlighted and in what is in the background. Once again, (24a) is not ambiguous in its meaning, the meaning being what is in the figure. Rather, it is its frequently ambiguous reference in certain types of situations that triggers the meaning shift to (24b). This seems to be the case especially in negative contexts, as in such contexts the unmentioned specific agent of (24a) becomes a non-existing agent (aqui no se habla inglés 'nobody here speaks English'). A non-existing agent is by definition also non-specific. The construction's frequent use in this type of situation enables the shift from figure to background. Only after the meaning change, the surface string se vende cerveza is semantically ambiguous insofar as it can be interpreted as an instance of both (24a) and (24b). Note that at this stage both interpretations are attached to the same syntactic analysis (namely 24a). This 
situation still prevails in Modern Standard Spanish. Substandard Spanish, however, has replaced syntactic structure (24a) by structure (24b) as early as in the 16th century, thus adapting the construction's syntax to its recently changed meaning. This shows that the meaning change (24) is a necessary (albeit not sufficient) condition for the syntactic reanalysis.

In this example, two competing semantic analyses are alternative interpretations in the utterance situation. Reanalysis enables two superficially identical, but semantically different, strings to refer to the same state of affairs. In other words, the semantic relation of the two structures must be such that they can have the same referent in a large number of cases, i. e., that their extensions overlap. Only metonymic and taxonomic relations can comply with this requirement. This is straightforward for taxonomic relations, as the extension of any hyperonym includes by definition the extension of any of its hyponyms. Also a large subclass of metonymies (including synecdoche) and their respective literal counterparts may happen to have identical reference in discourse, e.g., German Kind 'descendant'/"child'. However, a metaphorical reading can hardly ever have the same referent as its literal counterpart. Given that metaphor categorizes one entity in terms of another entity, it is by definition excluded that a metaphor and its literal counterpart have identical reference in discourse. A metaphor and its literal counterpart usually belong to different frames ("domain mapping", cf. Croft 1993), thereby excluding identical reference. ${ }^{13}$

In summary, the principle of reference and the principle of transparency as listeners" strategies require that the "old" and the "new" structure may have identical reference in discourse. However, having identical reference in discourse does not mean that their senses must be identical. Rather, the very fact of a reanalysis having occurred entails that listeners have made a different semantic analysis of the same surface string. The requirement of identity of reference imposes certain constraints on the nature of the semantic relation between the old and the new analysis. The theory presented so far suggests that semantic change is the really important phenomenon in reanalysis, and that rebracketing

13 This is also an argument against a tendency in recent theorizing to view grammatical changes as a mixture of metaphor and metonymy, a view that has been advocated in particular by Bernd Heine. Heine, Claudi and Hünnemeyer (1991: 74) claim that "both metaphor and metonymy are part and parcel of one and the same process [...]". Traugott and König (1991: 213) also postulate a division of labor of metaphor and metonymy, albeit in a different way: "[M]etaphor is largely correlated with shifts from meanings structured in the external described situation to meanings situated in the internal evaluative, perceptual, cognitive situation, and in the textual situation. Metonymy is largely correlated with shifts to meanings situated in the subjective belief-state or attilude toward the situation, including the linguistic one." Following our argument, grammatical changes which are based on invited or accidental inferences cannot comprise metaphor, because pragmatic inferencing requires that the extensions of what is said and of what is intended or understood overlap. This is impossible with metaphor. 
and relabeling of the constituent structure are merely dispensable side-effects. This idea will be pursued in more detail in the next subsection.

\subsection{On ambiguity and abduction in reanalysis}

In the literature, it is generally assumed that reanalysis is induced by abduction. In this section, this idea will be reconsidered against the backdrop of the theory outlined above, thereby enabling further refinements.

The prevailing view seems to be that reanalysis takes place in language acquisition: Children "misanalyze" strings from parents' speech in the sense that they assign these strings a grammatical structure that is not identical with the grammatical structure underlying parents' speech production. This idea is persuasively illustrated in fig. (26), adapted from Andersen (1973: 767).

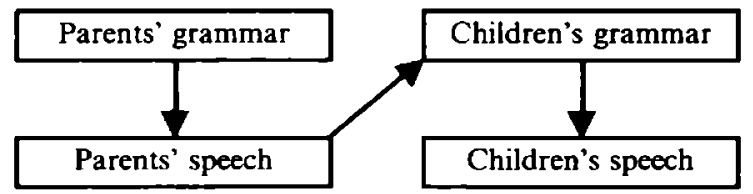

According to this view, reanalysis arises through an imperfect transmission of grammars from one generation to the next. Reanalysis as due to errors in language acquisition has been claimed to be a major source of language change, especially in generative studies (Roberts 1993a, Battye and Roberts 1995) but also in the functionalist tradition (Andersen 1973, Timberlake 1977, Haspelmath 1998). The alleged "errors" would then arise through abductive reasoning on the part of the listener. Abductive reasoning relates a given "result" (the surface speech string) to an underlying "case" (the grammatical structure of that speech string) via the reverse application of relevant "rules" (rules of grammar). If, still according to the mainstream point of view, the speech string is in some way ambiguous, the child may happen to invoke a rule that is not identical to the grammatical rule underlying the speaker's output, thereby assigning a "wrong" grammatical structure to the speech string. This "wrong" grammatical structure would then, in turn, yield innovative language use, as the child uses it in her/his own speech. This view calls for some comments:

As has been cogently argued by Croft (2000: 44-49), it is improbable that errors in language acquisition lead to language change because: (i) these errors normally disappear in later stages of acquisition and (ii) children do not normally have the social status required for the successful propagation of innovations.

According to the mainstream point of view, reanalysis appears as a largely free application of syntactic processes on constituent structures, regardless of 
possible concomitant semantic consequences of the new grammatical analysis. But, as has been argued in section 2, referential identity of the old and the new structure in discourse is a crucial prerequisite for reanalysis, thereby imposing severe constraints on the possibility of new structural analyses.

It is an error to assume that reanalysis requires a previous syntactic ambiguity, as is often claimed or presupposed in studies on reanalysis (cf. e. g. Timberlake 1977: 142, Harris and Campbell 1995: 72, Haspelmath 1998: 326). Structures that have undergone reanalysis are certainly syntactically ambiguous, but only as a natural result of, not as a prerequisite to, reanalysis. If there is a previous ambiguity, it is in the construction's reference to certain elements of the situation.

We propose that reanalysis, both in the reference-based and in the transparency-based version, can indeed be shown to be related to abduction, but in a way that differs with the traditional understanding of the phenomenon. The principle of reference and the principle of transparency are the respective "rules" in abductive reasoning.

ABDUCTIVE REASONING IN REFERENCE-BASED REANAL YSES. In a situation like the one described in section 2.1 above, the listener is confronted with an opaque sound chain L [lafjè] referring to a referent R (a DOG). This is the "result". He may now assume, as the underlying "case", that the conventional meaning of $L$ is $\mathrm{R}$, because the principle of reference as the "rule" states that a sound chain referring to a given referent has this type of referent as its meaning.

ABDUCTIVE REASONING IN TRANSPARENCY-BASED REANALYSES. In a situation like the one described in 2.2. above, the listener is confronted with an opaque sound chain $\mathrm{L}$ alicorno referring to a referent $\mathrm{R}$ as the "result". In order to make a grammatical analysis of that string, i. e., in order to find out the underlying "case", he may proceed as follows. Although $\mathrm{L}$ as a whole is opaque, it contains as a part of it a sound chain L' la [la] whose meaning P (i.e., definite determination of a feminine-gender noun) is already known to the listener. According to the principle of transparency (and the principle of reference) as the "rules", he assumes that $L$, as part of $L$, means $P$ in the situation under consideration, too. He therefore reckons that the meaning of $L$ is composed of $P$ and some further semantic component to be assigned to the still opaque part of $\mathrm{L}$, licorno. Both semantic components, $\mathrm{P}$ and the meaning of the opaque part of $\mathrm{L}$, refer as a whole to $\mathrm{R}$. Given that $\mathrm{P}$ means definite determination of a masculine-gender noun, the opaque part of $L$ must be analyzed as a femininegender noun denoting the type of $R$, in compliance with the principle of reference. Accordingly, the morphology of $\mathrm{L}$ is analyzed as consisting of two morphemes, [la] and [licorne].

This discussion is intended to show that reanalysis does not require a previous structural ambiguity. Such structural ambiguity is created by reanalysis. Reanalysis arises as listeners have problems in construing a morphological and semantic analysis of a given sound chain in a situation of communication. In 
re-analyzing that sound chain, listeners proceed indeed by abduction. However, this does not mean that reanalysis arises through the "wrong" application of some rule of grammar, as is often supposed. Rather, the rules that listeners apply in reanalysis are very general strategies of understanding. ${ }^{14}$ Therefore, there are in principle no structural constraints on reanalysis. Loss, shift, and creation of morpheme boundaries do not arise through some unmotivated manipulation of grammatical structures. Rather, they are a structural reflex of listeners' efforts to match sound chains with the apparently intended thing on one hand and other forms of the relevant language on the other hand, as claimed in (5b).

\section{Grammaticalization}

Two conflicting definitions of grammaticalization are proposed by Lehmann (1995a [1982]: 9) namely a) "[...] a process in which something becomes or is made grammatical", or, alternatively, b) as "[...] a process in which something becomes or is made more grammatical" (emphasis ours). Based on the second definition, Lehmann has worked out his ground-breaking theory, according to which competing grammatical devices of a given functional domain

[...] may be ordered on [...] a grammaticalization scale [...] set up according to a set of criteria which concern the autonomy of the language sign. [...] The grammaticalization of a sign detracts from its autonomy. Consequently, if we want to measure the degree to which a sign is grammaticalized, we will determine its degree of autonomy (Lehmann 1985: 305-6).

Loss of autonomy is a gradual, irreversible and unidirectional process involving all levels of language. It includes loss of phonological and semantic substance, shrinking of syntactic scope and of syntagmatic autonomy, disappearance of morphological boundaries as well as increasing obligatorification, i. e., loss of paradigmatic freedom. This view of grammaticalization encompasses the whole life-cycle of constructions and signs (Lehmann 1985:316) ${ }^{15}$ as well as the internal ordering of grammatical constructions and signs within given functional domains (Lehmann 1985: 311).

14 It might be that these strategies of understanding belong to the "laws of language" Andersen (1973: 776-8) was thinking of in his account of reanalysis. Following Andersen, the "laws of language" seem to be universal principles and constraints of linguistic structure that guide the listener in his inferencing process.

15 Lehmann (1985: 316) goes so far as to interpret morphological adjustments such as the tendency of German strong verbs to change into the weak conjugation as a grammaticalization phenomenon. 
A major problem is that this model provides neither a satisfactory explanation as to which factors trigger grammaticalization and determine its direction nor as to how the different levels of unidirectional change are interrelated. As Roberts has observed (1993b: 254), grammaticalization is still an explicandum rather than an explicans. An attempt to close this gap has been made by Haspelmath (1999). He hypothesizes that grammaticalization processes are initiated by speakers who "choose a new way of saying old things" (Haspelmath 1999: 1057, cf. also Hopper and Traugott 1993: 65) in order to be noticed by others, thereby behaving according to what Keller (1990: 132-9) calls the "maxim of Extravagance". However, given that such strategies are at work in all sorts of speakers' activities, this hypothesis clearly fails to explain why in some cases they result in grammaticalization, whereas on other occasions they trigger lexical change. In other words, it fails to capture the distinctive features which define grammaticalization. The same criticism holds for the more traditional explanation according to which grammaticalization is brought about by some unspecific form of expressivity (cf. Lehmann 1985: 314-7, 1995b: 1265, Hopper and Traugott 1993: 65).

Another shortcoming of Lehmann's framework is the place assigned to semantic processes. Together with phonological attrition, functional change characterized as gradual "semantic bleaching" - figures under the label of "loss of integrity" (Lehmann 1985: 307). This classification seems to suggest that both types of processes are to be regarded as isomorphic mutual corollaries. Such a view is in principle incompatible with our approach for obvious reasons. First, semantic shifts are discrete, not gradual. More importantly, semantic change is normally the cause of subsequent (syntactic, morphological and phonological) change of form rather than its by-product, as we have seen in the previous sections.

Lacking a functional foundation, Lehmann's framework can only be regarded as a taxonomic system, very useful for typological and comparative purposes (which, as follows from the passage quoted above, is indeed one of its intentions). It is not, however, a descriptive model with explanatory force. In the following sections we will therefore attempt to develop an independent view of grammaticalization in line with the cognitive and pragmatic parameters set forth in the first part of this paper. For this purpose we will limit ourselves to a detailed analysis of a single standard case, namely the evolution of the French negation (ne) pas 'not' (see (3)). In a first step, we shall illustrate the difference in scope of the competing definitions of grammaticalization outlined above. 
4.1. What kind of change is grammaticalization? The life-cycle of negative constructions

Negative embracing constructions like ne pas are characteristic of French as well as of other Romance languages. The respective negative or emphatic negative particles go back to Latin free nouns (see Schwegler 1988: 27, Krefeld 1997).

$$
\begin{aligned}
& \text { Negative particles in Romance (Old French, Catalan, Romansh): } \\
& \text { OF pas < L passu(m) 'step' C cap < L capu(t) 'head' } \\
& \text { OF point < L punctu(m) 'point' C gens < L genus 'kind (of)' } \\
& \text { OF mie < L mica (m) 'crumb' R betg }(a)<\mathrm{L} \text { bacca }(m) \text { 'berry' } \\
& \text { OF gote < L gutta }(m) \text { 'drop' R buc }(a)<\mathrm{L} \text { bucca }(m) \text { 'cheek(ful)', } \\
& \text { 'mouth(ful)', 'bite' }
\end{aligned}
$$

It is standardly assumed that these items' use as negative particles was originally motivated by Vulgar Latin constructions such as (28).

non passum vadere
non micam manducare
non punctum videre
non guttam bibere
non buccam manducare

'not to walk (even) a (single) step'

'not to eat (even) a crumb.'

'not to see (even) a point/spot.'

'not to drink (even) a drop.'

'not to eat (even) a cheekful/a mouthful/ a bite.'

In OF and Romance however, the items in question are used in contexts such as (29). Here, pas can no longer mean 'step', because this meaning would be incompatible with the sentence's main verb 'to be'. Thus, a change has taken place from (28), where the elements in question are free lexical units in the role of direct objects, to (29), where pas, like OF mie, point and gote, functions as a grammatical marker of emphatic negation meaning NOT AT ALL.

$$
\begin{aligned}
& \text { Ço'st Climborins ki pas ne fut prozdome } \\
& \text { This be:3sG Climborins who emph/*step NEG be:sG:PAST brave:man } \\
& \text { 'This is Climborins who was not a brave man at all.' (ChRol } 1528(1485) \text { ) }
\end{aligned}
$$

Techniques based on free lexical items for this purpose are supposedly universal cross-linguistically, even in those languages which, like OF, have grammatical elements of emphatic negation. Constructions of this type were abundant in OF (Möhren 1980): ${ }^{16}$

16 The existence of constructions such as (30) cannot be taken as evidence for the claim that in 12th century OF the "semantic transformation [from pas, 'step' to pas, '(not) at all', U. D., R. W.] was of fairly recent vintage" (Schwegler 1990: 154, see also Winters 1987: 35). 
(30) N'osa avant aler un pas 'he didn't dare to go even a step further' (En. 2596, cf. Tobler s. v. "Pas"), n'oncques de pain ne virent une mie, 'they never even saw a crumb of bread" (MAym. 2443, Tobler s. v. "Mie"), la ou il ne pleut nulle foiz goute d'yaue 'where it never rains even a drop of water' (Joinville 291), ne $m$ 'ont laissié une escalongne 'they haven't even left me an onjon' (Desch. $Q$ III 48, 28, cf. Möhren 1980: 109), ne mengastes morsel 'you didn't even eat a piece' (BaudSeb B VIII 168, cf. Möhren 1980: 169), n'en donroie un festu 'I wouldn't even give a straw for it" (Drei Fr. 192, Tobler s. v. "Doner") etc.

Free constructions and grammatical markers expressing emphatic negation are disjoint classes of constructions. ${ }^{17}$ OF ne pas, ne mie, ne point, ne gote are examples of originally free constructions that eventually turned into grammatical ones.

a. Emphatic negation and its expression in Latin and Old French

\begin{tabular}{|l|l|}
\hline \multicolumn{2}{|c|}{ emphatic negation } \\
\hline CONSTRUCTIONS WITH & $>$ GRAMMATICAL \\
FREE LEXICAL UNITS & \multicolumn{1}{|c|}{ CONSTRUCTIONS } \\
\hline $\begin{array}{l}\text { L non passum vadere, etc. } \\
\text { OF n'aler un pas avant, etc. }\end{array}$ & $\begin{array}{l}\text { OF Climborins ki pas ne fut } \\
\text { produme. }\end{array}$ \\
\hline
\end{tabular}

In OF, the "normal", unmarked negation was realized by ne alone. OF pas, mie, gote, point etc. were non-obligatory elements, used only when speakers wanted to place special emphasis on the negation. In the course of the 14th and 15th centuries, two of the grammatical markers of emphatic negation, point and pas, became increasingly frequent. Whereas in the 13 th century, ne was accompanied by pas in only $10 \%$ of its occurrences, in the 15 th century the co-occurrence of both particles was already the norm (von Wartburg 1971: 133 [1934], see also Gamillscheg 1957: 755, Marchello-Nizia 1979: 241). In close correlation to this development, point and pas came to lose their emphatic value (Schwegler 1988: 45-6, 1990: 155), so that henceforward ne point and ne pas as a whole functioned as "simple" negators:

Even today, i.e., some 800 years later, pas, has retained, along with its meaning 'step', its nominal value and can occur in free emphatic negative constructions such as II ne pouvait faire un pas sans un baton 'he could not take a single step without a walking stick'.

17 Hopper (1991: 26) and Hopper and Traugott (1993: 115) seem to confound both types of constructions, when they treat grammatical particles such as pas, point, mie, and gote and free lexical emphasizers like amende 'almond', areste 'fish-bone', beloce 'sloe', eschalope 'pea-pod' as elements of one and the same paradigm. 


\begin{tabular}{|c|c|c|}
\hline \multicolumn{2}{|c|}{1 emphatic negation } & \\
\hline $\begin{array}{c}\text { 1a CONSTRUCTIONS WITH } \\
\text { FREE LEXICAL UNITS }\end{array}$ & $\begin{array}{c}\text { Ib GRAMMATICAL } \\
\text { CONSTRUCTIONS }\end{array}$ & \\
\hline $\begin{array}{c}\text { L non passum vadere, etc. } \\
\text { OF } n \text { 'aler un pas avant, etc. }\end{array}$ & $\begin{array}{l}\text { OF Climborins ki pas ne } \\
\text { fut produme. }\end{array}$ & $\begin{array}{l}\text { Car plus fiere seroit de vous } \\
\text { Qu'elle na pas esté de nous. }\end{array}$ \\
\hline
\end{tabular}

Even though the embracing construction ne pas expressed simple negation as early as the 15 th century, it was not until the 17 th century that it had replaced the old negative ne in written standard French (cf. Haase 1965 [1889]: 250). By the same time however, in the informal registers of spoken French ne pas had already turned into a single-unit-construction again, the weak, proclitic ne being usually dropped (Ernst 1985: 85). This situation prevails until the present day:
Elle pensait
pas à elle en disant ça,
elle était
pas égoïste [...].
She think:3sG:PAST NEG of her in saying that, she be:3sG:PAST NEG egoistic.
'She didn't think of herself when she said that, she was not being egoistic.
(20th century, Queneau, Zazie)'

The entire cycle leading from non passum 'not a step' to pas 'not' can be represented as follows: ${ }^{18}$

$$
\text { c. The life-cycle of } F \text { ne pas }
$$

\begin{tabular}{|c|c|c|c|}
\hline \multicolumn{2}{|c|}{1 emphatic negation } & 2 simple negation \\
\hline $\begin{array}{c}\text { 1a CONSTRUCTIONS } \\
\text { WITH FREE } \\
\text { LEXICAL UNITS }\end{array}$ & $\begin{array}{c}\text { 1b GRAMMATICAL } \\
\text { CONSTRUCTIONS }\end{array}$ & $\begin{array}{c}\text { 2a BIPARTITE } \\
\text { CONSTRUCTION }\end{array}$ & $\begin{array}{c}\text { 2b SINGLE-UNIT- } \\
\text { CONSTRUCTION }\end{array}$ \\
\hline $\begin{array}{c}\text { L non passum } \\
\text { vadere, etc. } \\
\text { OF } n \text { ' aller un } \\
\text { pas avant, etc. }\end{array}$ & $\begin{array}{c}\text { OF Climborins } \\
\text { ki pas ne fut } \\
\text { produme. }\end{array}$ & $\begin{array}{c}\text { Car plus fiere } \\
\text { seroit de vous } \\
\text { Qu'elle } n \text { 'a pas } \\
\text { esté de nous. }\end{array}$ & $\begin{array}{c}\text { elle était pas } \\
\text { égoöste }\end{array}$ \\
\hline
\end{tabular}

18 For the sake of simplicity, we omit certain important details like the spread of pas from predicate negation to word negation like in il était fatigué. (non) pas malade (cf. Price 1971: 254-5, Schwegler 1990: 159-60). 
According to Lehmann's extensive definition, the whole cycle is a single grammaticalization process: an independent lexical item gradually turns into an obligatory, semantically light and syntactically fixed grammatical marker, after having gone through different stages of increasing paradigmatization. In the view summarized in $(31 \mathrm{c})$, however, the evolution of the embracing negative construction is made up of three different processes which do not all comply to the same extent with the above mentioned definitions of grammaticalization:

The step from 1 a to $1 b$, which turns constructions with free lexical units like non passum into grammatical constructions like ne pas, clearly represents "[...] a process in which something becomes or is made grammatical". It can thus be regarded as a model case of grammaticalization. The features that a pragmatic and cognitive analysis of this process will bring to light (section 4.2.), will be regarded as prototypical properties of grammaticalization.

The step from $1 b$ to $2 a$ turns an already grammatical construction, designed to mark a special, emphatic value, into the unmarked expression of simple negation. This change whereby pas becomes increasingly obligatory, is a possible candidate for "[...] a process in which something becomes or is made more grammatical" (see section 4.3.).

Whereas the steps from $1 \mathrm{a}$ to $1 \mathrm{~b}$ and from $1 \mathrm{~b}$ to $2 \mathrm{a}$ represent changes in meaning and function, the evolution leading from $2 \mathrm{a}$ to $2 \mathrm{~b}$ is a mere reduction of the construction's material form. Hence, this last step in the construction's life-cycle is most likely to represent a type of change that is different from grammaticalization (see section 4.4.).

\subsection{From lexical to grammatical}

Constructions representing stage $1 \mathrm{a}$ in table (31c) can probably be found in all languages. The reinforcing NPs, which function as negative polarity items not only in negative constructions but also in other highly specific contexts such as questions, conditionals etc. (Israel 1998: 27-57, Winters 1987: 35 , see also note 23 ), are not always entirely free, since they can be found in dictionaries of the respective languages.

(33) F ne pas remuer le petit doigt 'not to move the little finger', ne pas avoir l'ombre d'un soupfon 'not to have the shadow of a doubt', ne pas dire (un (seul)) mot 'not to say a single word', sans mot dire 'without saying a word', ne pas avoir le rond 'not to have a penny' etc.

(34) S non le quedaba una gota de vino 'not a drop of wine was left to him', no tener (la más remota) idea 'not to have the faintest idea', no mover un dedo 'not to lift a finger', no he pegado ojo en toda la noche 'I didn't 
close an eye all night (i. e., I didn't sleep a wink all night)', no lo he visto ni la sombra 'I haven't even seen his shadow'.

(35) L guttam haud sanguinis habere 'to have not even a drop of blood', non buccam panis habere 'to have not even a mouthful of bread', non pedem ab aliquo discedere 'not to deviate even a foot's width from sth.'

(36) E he didn't move an inch, I do not understand a thing, he didn't say a word. I didn't touch a hair on her, he didn't omit a single detail of his plan, I don't have the faintest idea, I don't have the least inkling, he doesn't care a fig etc.

However unsystematic this inventory may look - all the constructions in all the languages mentioned are instances of only one single discourse technique, i. e., a rhetorical rule of the following type:

(37) If you want to express in a strong way that some state of affairs did not take place at all, say that the state of affairs in question did not even take place to the smallest degree imaginable. In order to do so, take the negative form of the predicate and combine it with some direct or cognate object-NP which expresses the SMALLEST CONCEIVABLE QUANTITY affected or brought about by the state of affairs in question.

This procedural rule is designed for the negation of incremental states of affairs, i. e., states of affairs where (material) parts of the object affected or brought about correspond to (temporal) sections of the state of affairs as a whole (cf. Dowty 1991: 567-8), e.g. BUILD A HOUSE, WRITE A LETTER, EAT A CAKE. (37) is based on a strong pragmatic motivation which becomes transparent in contexts like (38):
a. A: Did you eat anything from the cake I made for uncle Alfred?
b. B: No, I didn't.
c. B: No, I didn't eat a crumb of that cake!
[Inference: You can verify yourself that nothing is missing!]

In everyday experience, (38b) does not explicitly exclude the inference that small, supposedly irrelevant increments of the state of affairs did in fact occur. In (38c), however, this possibility is explicitly excluded. Hence the difference between the unmarked negation in (38b) and the emphatic negation in (38c), where B is applying rule (37), is that in the latter case B formulates the strictest criterion imaginable by means of which the truth of his negative assertion can be verified. Accordingly, the degree of "communicative liability" which B assumes for the 
truth of his assertion is considerably higher in (38c) than it is in (38b). In contexts of emphatic predicate negation, asserting the truth of one's statement is a crucial and frequent problem, because

negative assertions are used in language in contexts where the corresponding affirmative has been mentioned, deemed likely, or where the speaker assumes that the hearer - erroneously - holds to a belief in the truth of that affirmative (Givon 1979: 107, see also Ducrot 1980: 49-56).

Typical contexts to which these characteristics apply are critical statements or accusations that the speaker has to counteract. For the solution of such a basic and frequent problem, speakers develop rhetorical routines, which mark the starting point of grammaticalization processes. The idiomatic expressions listed in (33) - (36), but also the grammaticalized emphatic negative marker in (29) represent different stages of such routines. ${ }^{19}$ The purpose of linguistic routines is to decrease the speaker's/listener's cost in encoding and decoding (cf. Hopper and Traugott 1993: 64-5). As prefabricated, problem-solving procedures to which little attention is paid they tend to become part of the message's background (cf. Haiman 1994: esp.9), thereby conforming to the general principle that recurring experiences lose their perceptual saliency (Givón 1979: 346). Grammaticalization in general can be conceived of as a progressive routinization of constructions (Lehmann 1993: 327). Since routines are designed to solve some frequently occurring problem, they are, by definition, frequent themselves. How does frequency affect the structural properties of constructions?

The first consequence of a given construction's routinization is that it becomes part of the language's inventory of idiomatic expressions. This means that it is increasingly used in a certain form, while other possible forms are progressively excluded. Thus, for the purpose of emphatic negation, certain verbs are preferably combined with particular nominal lexemes, e.g., the verb say with the noun word as in he didn't say a word. The nominal lexemes tend to occur either without any attributes at all or they combine with particular attributes rather than with other possible ones. In English, the norm is he didn't say a word or he didn't say a single word. More complex variants of the same construction such as he didn't say a solitary word or he didn't even say two miserable words do not correspond to the norm, which is itself brought about and sanctioned by high frequency. In later stages of the development, the nominal constituents are completely frozen, as in I don't care a farthing or I don't care a brass farthing, possible complex variants such as *I don't care a single farthing or *I don't even care two farthings being excluded. As a consequence of idiomaticization, the

19 Routinization and idiomaticization as part of grammaticalization processes are mentioned, although in a rather unspecific way, in Hopper and Traugott (1993: 64-5). 
nominal constituents gradually become invariant, which is tantamount to a loss of their nominal properties. In (39) small $n$ represents a former NP which has lost its nominal properties. This process takes place independently of the element's reanalysis as a grammatical marker of emphatic negation. Its gradual nature is based on the fact that frequency. by definition, is a gradual phenomenon.

$$
n e g[\mathrm{~V} \mathrm{NP}]_{\mathrm{vP}}>\operatorname{neg}[\mathrm{V} \mathrm{n}]_{\mathrm{v}}
$$

The step from NOT a STEP. NOT A POINT, NOT A CRUMB etc. to NOT AT ALL is a semantic change. Its direction is determined by the rhetorical technique described in (37). In order to attain a desired communicative effect, speakers do not say directly what they mean. i.e., they do not express a straightforward emphatic negation of the type I didn't walk at all. Rather, they invoke the concept (NOT A) STEP, which, in combination with WALK, is in metonymic relation to the concept NOT AT ALL (Winters 1987: 34): someone who DID NOT (EVEN) WALK A STEP obviously DID NOT WALK AT ALL. Note that, even though NOT (EVEN) WALK A STEP and NOT WALK AT ALL have the same referent, NOT A STEP and NOT AT ALL are not synonyms - NOT A STEP can only be used to refer to the concept NOT AT ALL within the frame of PHYSICAL MOVEMENT, that is, in combination with verbs like TO RUN, TO WALK etc. Hence, in such contexts, a construction of the type NOT WALK A STEP is better suited to express emphatic negation than NOT WALK AT ALL, not because it is more "extravagant" (cf. Haspelmath 1999) but because it is more informative. This type of rhetorical strategy, i. e., a semantic difference between what is said and what is meant, deliberately set up by speakers in order to be more informative than required, will henceforward be referred to as expressivity.

\section{a. Speaker's perspective: building up expressivity}

\begin{tabular}{|c|c|c|c|}
\hline & non vado passum & NOT A STEP & NOT AT ALL \\
\hline $\begin{array}{c}\text { expressive means } \\
\text { (thing said) }\end{array}$ & 'I do not walk a step' & ground \\
\hline thing meant & 'I don't walk at all' & ground & \\
\hline
\end{tabular}

The understanding of expressivity outlined above is at variance with the traditional use of the term, which covers all sorts of manifestations of the speaker's self (cf. Bühler 1982 [1934]: 28, Jakobson 1981: 22, Mair 1992: 104ff., esp. 110, 124). Rather, it characterizes a basic type of strategy on the part of speakers who say more than they must in order to achieve certain rhetorical effects (see Israel 1998: 109-10, Blank 1999: 63-6, 80-83). The purpose of expressivity is to efficiently convey speakers' attitudes towards propositional 
contents (Israel 1998: 105). It is effective in lexical change, in functional change within the grammar as well as in change from lexicon to grammar (cf. Koch and Oesterreicher 1996). As a type of speakers' strategy, aimed at rhetorical speaking, expressivity is opposed to reanalysis, which, as we have seen in the first part of this paper, is a listeners' strategy, designed for understanding. As a type of "emphatic" strategy (Israel 1998: 105) whereby speakers are more informative than necessary, expressivity is opposed to speakers' strategies of "understatement" which consist in conveying less information than required, such as euphemisms (cf. Blank 1999: 81, Israel 1998: 109), indirect speech acts as well as indirectness in general (cf. Israel 1998: 105-10). ${ }^{20}$

Expressivity is built up by speakers who try to speak efficiently. The loss of expressivity and the subsequent change in meaning, however, are brought about by listeners who understand the expressive construction and conventionalize their understanding. Meaning change is always ratified by listeners. To understand an expressive construction means to replace the thing literally said by the speaker ( NOT A STEP) by what he really seems to mean, namely emphatic negation of the type NOT AT ALL. This operation is an instance of reanalysis, whereby the listener who proceeds according to the principle of reference (9) assumes that the real meaning of what he hears (NOT A STEP) is what seems to be referred to in the situation (NOT AT ALL). Thus, in order for a meaning change to occur, the expressive technique represented in fig. (40a) has to be accompanied by a reanalysis of the type represented in fig. (40b).

b. Listener's perspective: reducing expressivity (in conformity with principle of reference)

\begin{tabular}{|r|c|c|c|}
\hline & non vado passum & NOT A STEP & NOT AT ALL \\
\hline thing heard & 'I do not walk a step' & fgere & ground \\
\hline $\begin{array}{l}\text { thing presumably } \\
\text { meant by speaker }\end{array}$ & 'I don't walk at all' & ground & figure \\
\hline
\end{tabular}

As an immediate consequence of this meaning change, the small $n$, the output of (39), turns into a marker of emphatic negation (41). In other words, rebracketing and categorial re-labeling are direct corollaries of the metonymic change represented in fig. (40b).

20 Functional change based on indirectness includes subjectification (cf. Traugotl and König 1991, Traugott 1995), since this type of change is triggered by speakers who are less informative than required, but allow the hearer "the option of reaching the stronger interpretation" (Traugott 1995: 49, see also Traugott and König 1991). 


$$
n e g[\mathrm{~V} \mathrm{n}]_{v p}>n e g / \mathrm{V} \backslash e m p h
$$

Note that even though $n$ is gradually de-nominalized by idiomaticization (see (39)), it becomes a member of a new functional class only by means of the metonymic shift and the concomitant reanalysis (40b). Only this step enables it to appear in contexts other than with verbs of PHYSICAL MOVEMENT (see ex. (29)). Without this change, it would remain a frozen nominal within a phraseological unit.

Like any semantic change, this process is abrupt, not gradual. While it is true that passum can be polysemous. i. e.. have two discrete meanings at a time (as is still the case with F pas, see note 16). any sort of intermediary concept combining properties of STEP and (NOT) AT ALL is unthinkable. Hence, passum either means STEP or (NOT) AT ALL. Since the syntactic structures in (41) are immediate reflexes of the two discrete conceptual interpretations, it follows that they, too, must be discrete entities. In light of these arguments, the claim that conceptual change in grammaticalization represents "a continuum without any clear-cut internal boundaries" (Heine, Claudi and Hünnemeyer 1991: 67) seems problematic.

What exactly is the difference between the reanalysis represented in fig. (40b) and the types of reanalyses discussed in sections 2 and 3 of this paper? Note that in the case of fig. (40b), listeners only reduce expressivity that has been built up by speakers beforehand (fig. (40a)). It is the expressive discourse technique in fig. (40a), i. e., a speakers' activity which determines the direction of the change. So, unlike in cases of "simple" reanalyses discussed in section 2 and 3 , the listeners" contribution in fig. (40b) does not account for the direction of the change. The logical conclusion is that grammaticalization is best described as brought about by speakers who want to speak convincingly. Grammar is the reanalyzed residue of expressive routines. "Pure" reanalyses, on the other hand, are exclusively brought about by listeners who attribute meaning to segments of speech, that is, who try to understand.

The meaning change discussed in this section (see figs. (40a) and (40b)) is facilitated by the construction's high frequency. As a consequence of routinization, less attention is being paid to the construction's literal meaning. High frequency favors the reanalysis NOT A STEP > NOT AT ALL (see section 2.1.). Nevertheless, the statement that "repetition drains meaning from words" (Haiman 1994: 12) is much too strong. Meaning is not "worn out" by frequent use (Detges 1999: 32-3, Haspelmath 1999: 1052), but rather, new meaning arises as a consequence of speakers' strategies and/or of reanalyses on the part of listeners. The direction of grammaticalization as well as the frequency of grammatical items can more adequately be explained by the view that grammar as a whole is essentially a set of linguistic routines conventionalized to the end of solving certain basic communicative problems (cf. already Givón 1979, esp. $87-90$ ). 


\subsection{From grammatical to more grammatical}

The step from emphatic to unmarked negation (i. e., from 1 b to $2 \mathrm{a}$ in table (31c)) is generally explained as a case of "pragmatic unmarking" whereby "the pragmatic component [i.e., the construction's emphatic value, U.D., R.W.] is lost through frequent use" (Vennemann 1974: 158, see also Haspelmath 1999: 1062). This view is pointed out in more detail by Schwegler (1988. esp. $47-9$ ).

Since negation - at least in spoken discourse - frequently occurs in contexts where the hearer's assumption of the truth of the corresponding affirmative is to be rejected or opposed, the presuppositionally marked construction [i.e., the marker of emphatic negation U.D., R.W.] is likely to increase in frequency. A significant increase in frequency [...] may gradually lead to a loss of its presuppositional value. whence speakers may extend the use of the construction to all negative predications (Schwegler 1988: 48).

According to this point of view, emphatic negative markers will automatically turn into simple negators. This argumentation suffers from a major shortcoming. As long as grammatical constructions are used in the way generally accepted by the speech community, i. e., in contexts in which the conventional conditions of their use are satisfied, they will remain functionally stable, whatever their frequency. In other words, since it is their normal function to be used in such contexts, this cannot change their function. More specifically, emphatic negatives are not expressive per se. because in contexts of strong counterexpectation, they are exactly as informative as required (later in this section, we will see what an expressive use of emphatic negatives looks like). However, for a grammatical construction to be used expressively, that is, to be employed (and accepted) in some new and unusual context, it takes a particular motivation. Of the OF emphatic negative particles brought about by the mechanisms described in section 4.1., namely pas, point, mie and gote, only pas and point turned into markers of simple negation. Besides the constructions mentioned, OF made use of the emphatic negatives ne aucunement and ne nulement, which are still employed today in formal speech. In Modern French, the most current emphatic negative construction is (ne) pas du rout, in use as early as the 16th century. In spite of the fact that all of these constructions had, during long periods of their history, or still have, a high frequency, neither of them has shown the slightest symptom of losing its emphatic value. Hence, there can be no self-acting tendency of emphatic negatives to turn into unmarked ones. Rather, it seems that something particular must happen before a marker of emphatic negation can turn into a simple negation marker. This is what actually happened in the history of ne pas. The rise in frequency which accompanied the loss of this 
construction's emphatic value occurred within a clearly identifiable and limited time-span (see section 4.1.). ${ }^{21}$

As already pointed out in section 4.2., markers of emphatic negation are used whenever speakers want to act against some strong counter-expectation on the part of their listeners (cf. already Martin 1972: 43). This function explains why $\mathrm{OF}$ and MF pas, point, mie as markers of emphatic negation were particularly frequent in the context of ainz aingoiz 'rather', but' and mais 'but' (Offord 1976: 333. see also Schwegler 1988: 45-6). In such contexts, they normally indicated the unexpected and surprising character of some negative assertion.

$$
\begin{aligned}
& N \text { estoit mie de veir pele La forreüre, ainz ert de sables } \\
& \text { NEG be:3sG:PAST emph of skinned miniver/The fur, but be:3sG:PAST of sable. } \\
& \text { 'The fur [which lined the coverlet. U. D., R. W.] was not at all skinned miniver } \\
& \text { [inference: as one should expect]. rather, it was sable [inference: this fact is } \\
& \text { remarkable]." (ChChar 508/9) }
\end{aligned}
$$

States of affairs that are surprising are maximally informative. In other words, they conform highly to the Gricean maxim of Relation ("be relevant", cf. Grice 1975: 46). Since they appear particularly worthwhile being uttered and listened to, they offer considerable communicative advantages to the speaker. Any participant in a conversation who utters such states of affairs will valorize her own status vis-à-vis her interlocutors.

This situation contains a strong motivation for a process that will eventually turn markers of emphatic negation into simple negators. Speakers can choose to "abuse" markers of emphatic negation in order to pretend that the negative assertion of some state of affairs which they are about to utter is particularly surprising and relevant. This effect can be achieved by using a marker of emphatic negation without the conditions for its use, i.e., a high degree of counter-expectation on the part of the listener, being fulfilled. Such a rhetorical technique is expressive in the sense outlined in 4.2. to the extent that the speaker is more informative than required. Making one's contribution appear as relevant as possible is a crucial and frequently occurring communicative

21 It has to be mentioned, however, that this view is not uncontroversial. It is supported by "orthodox" authors like von Wartburg (1971: 133 [1934]) and Gamillscheg (1957: 755). Others, like Price (1971: 252) and Jensen (1990: 425) doubt that OF pas, mie and point had any emphatic value at all. However, the facts presented by the proponents of the latter position are somewhat contradictory. Thus, Jensen (1990: 425) admits that "the negation auxiliaries may occasionally precede $n e$, in which case a certain notion of insistence is added [see, e. g. (29), U. D., R. W.]".

22 In the Roman de Berinus (ca. 1350-1370), sentences containing ainz, ainfoiz and maiz constitute by far the most frequent contexts of all uses of point, pas and mie. They amount to approximately $25 \%$ of all occurrences ( 99 out of 444 ) of the emphatic negatives (see Offord 1976: 333). On the other hand, the unmarked negative ne occurs significantly more seldom in such contexts than the emphatic negatives (34 vs. 99 occurrences in Berinus, see Offord 1976: 333). 
problem. If the technique of expressive relevance-marking in contexts of negative assertions is deemed efficient by other speakers, it will turn into a "fashion of speaking", that is, into an expressive routine. Routinization will in turn lead to a rapid increase of the emphatic negative marker's frequency. Thus, increase in frequency is not a cause of functional change. Rather, it is a symptom of a foregoing change in a construction's use or function (see also Haspelmath 1999: 1062).

The speakers" motivation of "abusively" marking the relevance of their contributions starts off an inflationary invisible-hand-mechanism (Keller 1990) that finally leads to a paradoxical result. If an emphatic negative marker is repeatedly used to mark negative assertions which in reality are not especially relevant, it will by degrees lose its emphatic value and turn into a marker of simple negation. Once again, the final change in meaning is brought about by listeners who reanalyze the expressive technique in accordance with the "principle of reference", by replacing what they hear (NOT AT ALL) with some interpretation which seems more in conformity with the type of negative state of affairs actually referred to by the speaker (i.e., simply NOT). As in the case discussed in section 4.2., the listeners thereby only reduce expressivity which has been built up by speakers before, so that, in this case as well, the direction of the change is exclusively determined by the speakers' strategy of expressive relevance-marking. For the sake of simplicity, fig. (43) does not differentiate between the perspective of the speaker and that of the listener.

What distinguishes emphatic negation from normal, unmarked negation is the fact that it is a special kind of negation. In other words, emphatic negation is a hyponym of unmarked negation. This relation manifests itself in the syntactic structure of two-part emphatic negative constructions (Fig. (31c), stage 1b). In OF ne mie, ne pas or ne point, both constituents have clearly distinct functions: the obligatory negative ne represents (unmarked) NEGA TION as such, whereas the non-obligatory particles mie, pas or point express the additional feature EMPHASIS. The development of ne pas and ne point from emphatic to simple negation means that, as a consequence of the feature EMPHASIs being lost, the constructions' meanings turn into their own hyperonyms. Thus, we are dealing with an instance of taxonomic change, more precisely with semantic widening. 


\begin{tabular}{|c|c|c|c|}
\hline & ne V pas & $\begin{array}{c}\text { [feature 1:] } \\
\text { NEGATIVE } \\
\text { ASSERTION }\end{array}$ & $\begin{array}{c}\text { [feature 2:] } \\
\text { EMPHASIS }\end{array}$ \\
\hline $\begin{array}{c}\text { expressive means } \\
\text { (thing said by the } \\
\text { speaker } \\
\text { the listenerd by }\end{array}$ & 'V is not the case at all: & & $\begin{array}{c}\text { FIGH DEGREB } \\
\text { OP } \\
\text { BELEVANCE }\end{array}$ \\
\hline $\begin{array}{c}\text { state of affairs } \\
\text { referred to }\end{array}$ & V is not the case. & & $\emptyset$ \\
\hline
\end{tabular}

The mechanism represented in fig. (43) is different from metonymic change in that the element which eventually turns into the new function (NEGATIVE ASSERTION) is not a contiguous background-concept, but already part of the construction's original conventional meaning. This shift takes place because some communicative effect (HIGH DEGREE OF RELEVANCE), which is attached to an element of the old meaning (EMPHASIS), is brought into focus and is finally "used up" as a consequence of the above discussed invisible-hand-process. The construction's new meaning is the residue of this process. Unlike the change which turned NOT A STEP into NUT AT ALL, the new meaning of the construction has nothing to do with the communicative purpose that the expressive routine is designed to achieve. In other words, in the case under consideration here, the product of the change is not a more efficient routine of communication, but the unintended, random by-product of a strategy of "abusive" relevance-marking.

This type of change is extremely common. It affects emphatic or marked constructions in all sorts of functional domains. The very same pragmatic and semantic mechanisms, i. e. "rhetorical devaluation" (Dahl 1998) and subsequent semantic widening, are at work e.g. when demonstrative pronouns turn into definite articles (Laury 1997), when marked topic shift constructions become canonical sentence structures (Givón 1976), or when markers of a past tense with present relevance lose their present relevance via some rhetorical "hot news" strategy (Schwenter 1994) and come to express an unmarked past tense.

However, change based on expressivity does not have to occur (Hopper and Traugott 1993: 95). The change of a construction of emphatic negation into a marker of simple negation requires speakers who discover the rhetorical potential inherent in a systematic "overuse" of emphatic negation, and other speakers who install a new "fashion of speaking" based on this rhetorical strategy. If these conditions are not met - which is the normal case - no change will occur. Emphatic negative constructions which turn into normal negatives are, statistically speaking, the exception rather than the rule (see discussion 
above in this subsection). On the other hand, the strong pragmatic motivation of marking the relevance of negative assertions explains why, among all the types of functional change which can possibly affect emphatic negative constructions, the shift towards simple negation is relatively likely and frequent.

From Lehmann's perspective, grammaticalization of a construction is a single, gradually advancing, unidirectional process. According to what has been said so far, however, the whole cycle leading from $L$ non passum 'not a step' to $F$ (ne) pas 'not' is made up of two discrete functional shifts. Note that the ordering of these shifts is not random insofar as the constructions that serve as input to the second step are typically brought about by the first one. but not vice versa. Both processes are independently motivated, but they are intrinsically ordered. This is an important point since it is part of the explanation of unidirectionality of grammaticalization (see below, section 4.5.). However, contrary to what Lehmann's model predicts, not all items expressing emphatic negation are pushed "gradually and simultaneously along the stages of a scale" (Lehmann 1985: 311), but only those which have been selected by speakers for the second process, i. e., the rhetorical strategy of relevance-marking.

\subsection{Morpho-syntactic consequences of functional change}

As a result of its reanalysis sketched in fig. (43), the construction undergoes further relabeling and rebracketing. When the former carriers of emphasis, pas and point, are reanalyzed as non-emphatic, obligatory elements, the negative construction as a whole changes its internal structure: what so far has been a complex construction, consisting of two constituents, now turns into a single (albeit formally discontinuous) functional unit:

$$
\text { neg } \mathrm{V} \text { emph }>\text { neg } \mathrm{V} \text { neg }
$$

The construction's further development is characterized by an adaptation of its grammatical properties to the new underlying semantic function. Unlike the functional shift itself (see end of section 4.3.), its material consequences seem to be, to a certain extent at least, predictable. The most spectacular consequence of the reanalysis is the ellipsis of ne (see section 4.1.). ${ }^{23}$

23 Like all negative polarity items in all languages, pas, mie and point could figure alone in hypothetical and interrogative contexts much earlier already (cf. Marchello-Nizia 1979: 244-5, Gamillscheg 1957: 754-5, Ernst 1985: 85, note 114 and 88). Even though some authors (Harris 1978: 26, Mair 1992: 293, 295) view such uses as early precursors of the modern ellipsis of ne, both phenomena are completely independent of each other. 
It might be argued that ellipsis of $n e$ is not a direct consequence of the reanalysis (44), since universally, the old unmarked negative element can, under certain conditions, be omitted already in emphatic negative constructions. Thus, in modern French pas:NEG du tout:EMPH (Haas 1916: 452) or ne:NEG aucunement:EMPH (Robert Electronique s. v. "Aucunement"), in Brazilian Portuguese não:NEG não:EMPH (Thomas 1969: 289) or in Italian non:NEG affatto:EMPH (Zingarelli s.v. "Affatto"), the emphatic element can stand alone in elliptical replies to alternative questions which can only be answered by "yes" or (emphatic) "no":

$$
\begin{aligned}
& \text { Est -ce votre avis? } \\
& \text { Be:3SG:PRES -this:INTERROG your opinion? } \\
& \text { 'Is this your opinion? - Not at all!' }
\end{aligned}
$$

In situations of the type represented by (45), the presence of pas is not really necessary, since its content is unambiguously inferable from the occurrence of $d u$ tout. Hence, in such contexts - but only in such contexts -, the full construction would present a high degree of formal redundancy. The ellipsis of the unmarked negative is reduction of such redundancy.

Only as an immediate consequence of the rebracketing mechanism (44), formal redundancy is generalized to all contexts, because now the reanalyzed construction structurally contains two items which are equally labeled NEG. As a reaction, the ellipsis of $n e$ is generalized to all sorts of contexts as well. By way of this process, a "simple" function such as unmarked negation comes to be represented by a morphosyntactically "simple" form. The direction of this change is determined by the principle of constructional iconicity (Mayerthaler 1977: 34-5, 1981: 23-34). Even though this morphosyntactic process can be regarded as a direct consequence of the preceding functional change, it clearly is of an entirely different nature: its objective is not efficient rhetorical speaking; rather it is aimed at restoring the speakers' ease in processing the construction. This type of change is not specific to grammaticalization as such. Hence, the term grammaticalization can only be legitimately applied to the functional shift as such, not to its predictable material consequences, which are governed by other principles.

In 4.2., we have rejected the idea that functional change in grammaticalization is gradual. Obviously, this does not hold for the material consequences of grammaticalization. The generalized ellipsis of the unmarked negative is a continuation of an earlier process. However, the spread of innovative features does not occur in a monotonic fashion. Generalized ellipsis of $n e$, for instance, could not occur before pas had turned into a non-emphatic obligatory element (section 4.1.). By the same token it can be predicted that the modern French emphatic negative pas du tout will categorically exclude ellipsis of pas in contexts other than the ones represented by example (45) as long as it remains 
functionally stable. If however its function should ever turn into that of a simple negative, omission of pas will most probably occur soon afterwards in all kinds of contexts. This change will likely appear first in the informal registers of spoken French. Thus, in those dimensions of language change that are gradual in nature, grammaticalization is manifested by sharp curves.

\subsection{What is grammaticalization?}

As a consequence of the conclusions drawn in this section, it would seem necessary to distinguish between grammaticalization proper, which is a purely functional type of change, and the processes of formal adaptation accompanying or following it. Grammaticalization is a process whereby a lexical item assumes a grammatical function or whereby an already grammatical item takes on a more grammatical function. Hence, only the shifts discussed in sections 4.2. and 4.3. represent grammaticalization. The model case is provided by the change from NOT A STEP to NOT AT ALL, that is, from constructions consisting of free lexical units to grammatical constructions (see section 4.2.). The shift from NOT AT ALL to NOT, i. e., from emphatic to simple negation (see section 4.3.) displays some basic similarities with the model case: in both examples, the change brings about the routinization of an expressive technique, aimed at meeting the requirements of the Gricean Maxims of Quality and Relation respectively in particular types of contexts. Grammar as a whole can be viewed as the sum of such routines. As we saw in section 4.2. however, the target concepts of grammaticalization processes may in some cases be nothing more than the random by-products of expressive routines. Moreover, such shifts may bring about structural redundancy. Hence, the grammar of a given language also contains the frozen, de-motivated residues of expressive routines, which do not serve particular functional or communicative purposes any more (cf. Lehmann 1985: 316, see also Givón 1979: 261-4 on “crazy syntax").

Our argumentation challenges the view that grammaticalization is gradual (Haspelmath 1998: esp. 326). If grammaticalization is, as we argue, a basically functional type of change, it cannot be gradual, since functional shift is abrupt change between discrete entities (section 4.2.). Moreover, the evolution which led from $\mathrm{L}$ non passum to Modern $\mathrm{F}$ (ne) pas was not a single, continuous process, advancing in a strictly linear fashion. Rather, it was driven by two discrete and independent functional shifts, which however are intrinsically ordered (see section 4.3.). Undoubtedly, both of these shifts were preceded, accompanied and followed by processes that have a gradual dimension. For instance, frequency is an inherently gradual phenomenon (section 4.2.). A sudden rise in frequency - as an immediate consequence of grammaticalization is the gradual expression of abrupt functional discontinuity (section 4.2.). This means that functional change is reflected on the material level in gradual, but non-monotonic developments. 
It has often been observed that grammaticalization is a unidirectional and irreversible process (Lehmann 1985: 315, Hopper and Traugott 1993: 94-129, Haspelmath 1999 etc.). The account presented in this paper explains why this is so. In the first place, the development from $L$ non passum 'not a step' to $F$ pas "not" is unidirectional and irreversible as a whole a) because each of the two underlying functional shifts is individually unidirectional and irreversible, and b) because both shifts are intrinsically ordered insofar as the constructions that serve as input for the second one are typically the output of the first (see end of section 4.2.). In sections 4.2. and 4.3.. we have argued that grammaticalization processes normally start out as expressive speakers' techniques. When such a technique leads to meaning change in a given construction, its original expressivity is lost as a consequence of reanalysis (see section 4.2.). Any meaning shift based on expressivity is irreversible because expressivity that is lost cannot be restored. Thus, today (ne) pas cannot be employed as a marker of surprise and relevance any more, since its emphatic value has been "used up" by the expressive technique described in section 4.2. Moreover, we saw that grammaticalization specifically consists in the routinization of such expressive techniques (section 4.2.). This dimension of grammaticalization provides another source of irreversibility. Frequent linguistic routines to which speakers pay little attention cannot be "de-routinized", i. e., they cannot be made to occur more rarely in order to appear fresh and surprising (Haspelmath 1999: 1061). They can only be abandoned or replaced by new routines, deemed more expressive by the speakers (Hopper and Traugott 1993: 65).

Haspelmath (1999: 1062) states that what he calls "the semantic aspect" of grammaticalization is not irreversible insofar as lexical meanings can be derived from grammatical ones. Thus, the grammatical item if has served as a derivational base for the adjectival lexeme iffy as in an iffy proposition 'a proposition containing many contingencies and unknown conditions' (cf. Lehmann 1995b: 1256a). However, while it may be true that the semantic development in grammaticalization is not irreversible, it clearly is unidirectional in the sense that the conceptual shift from IF to QUALITY OF AN UTTERANCE CONTAINING MANY ifs will predictably never lead to the emergence of grammatical meaning. Why is this so? As we have argued in sections 4.2. and 4.3., typical motivational triggers for grammaticalization processes are frequent and important communicative problems, such as, e.g., indicating a high degree of communicative responsibility in certain problematic contexts. For the solution of such problems, speakers make use of rhetorical techniques like rule (37) which provides that, in order to express emphatic negation of states of affairs involving PHYSICAL MOVEMENT, it may be advisable to use nouns denoting the concept STEP. Hence, it is rule (37) which determines the direction of the change from NOT A STEP to NOT AT ALL. This account predicts that grammaticalization in the inverse direction, i.e., from NOT AT ALL to NOT A STEP is extremely unlikely. It could occur only under two conditions, namely a) if the reference to the concept STEP 
was a context in which indicating one's communicative responsibility was a frequently occurring problem, which would make it necessary to develop rhetorical techniques and linguistic routines, and $b$ ) if a rhetorical technique of reference to this problematic concept involved the use of an item meaning NOT AT ALL. It is hard to imagine under what circumstances any of the two conditions could be satisfied.

It has often been claimed that the source concepts of grammaticalization processes have a privileged cognitive status. However, the source concepts of negative constructions such as STEP, POINT, CRUMB Or DROP are most unlikely to form part of the "alphabet of human thoughts" (Heine et al. 1991: 33) and certainly, they do not "belong to the universal set of semantic primitives" (ibid.). As follows from our argumentation, the feature which makes them eligible for grammaticalization is the fact that they prove to be useful within the simple rhetorical strategy (37). On the other hand, it is clearly part of the universal alphabet of human behavior to underscore that one's words correspond to the truth and that they deserve the listener's attention. Hence, if anything, it is the motivation underlying the target concepts, that is, the communicative needs underlying grammar, which has the more fundamental status.

\section{Comparing the incomparable: Grammaticalization and reanalysis}

As has become clear from our argumentation, grammaticalization and reanalysis are neither inseparable nor twins. They do not even belong to the same level of abstraction. It has already been observed that reanalysis is the more fundamental phenomenon (Hopper and Traugott 1993: 32-50, Harris and Campbell 1995: 20), since it occurs in any type of functional change. The purpose of reanalysis is understanding. Hence it is not grammaticalization that is its direct counterpart, but rather the very general speakers' strategies mentioned in section 4.2., i. e., expressivity and indirectness. Grammaticalization is only one subclass of change based on expressivity. Moreover, it is always accompanied by reanalysis. It follows from this observation that, contrary to Haspelmath's (1998: 344) claim, grammaticalization cannot be the more important phenomenon.

Reanalysis is, as we have seen, not entirely "non-directional". Its specific directionality is governed by strategies of understanding. These strategies are fundamentally different from those that guide grammaticalization. Grammaticalization, which is a very specific type of expressive change triggered by highly particular communicative motivations, has a strong inherent directionality. Moreover, the possible steps in a grammaticalization chain, i. e., the steps from lexical to grammatical or from grammatical to more grammatical, are, as we have argued in 4.3., intrinsically ordered. Ultimately, this order is due to the constraint that only certain concepts lend themselves to certain thetorical 
strategies. Reanalysis, on the other hand, which is a very general mechanism of change, has a rather unspecific directionality. It can lead from more to less complexity, but also from less to more complexity, or from one kind of complexity to a different kind of complexity of the same degree. Moreover, there is no intrinsic order inherent in chains of reanalyses, because there are no constraints on reanalysis itself (cf. section 2). There are no limits to what is not understood.

As a type of functional change. grammaticalization is as abrupt as reanalysis. By the same token, the formal processes accompanying reanalysis, e.g., the gradual fusion of sheep-herd to shepherd, are of the same nature as the formal processes accompanying grammaticalization. Why, then, doesn't reanalysis behave according to Lehmann's parameters? The answer to this question has to do with the different kind of directionality of both types of change. Grammaticalization has a strong directionality. which, as we have argued, is functionally based. The formal changes as set out in Lehmann's parameters only reflect this functional cline. In chains of reanalyses, however, there is no intrinsic order. Hence, formal changes accompanying reanalyses do not proceed along predictable lines.

\section{Sources}

$\mathrm{Ch}$ Rol = La chanson de Roland: Oxford version. Ed., notes and glossary by T. Atkinson Jenkins. With a new bibliographical suppl. by Gerard J. Brault 1977 [1929]. Watkins Glen, NY: American Life Foundation.

ChChar = Chrétien de Troyes. Lancelot, or The Knight of the Cart (Le Chevalier de la Charrete). Edited and translated by William W. Kibler 1981. New York, London: Garland.

Joinville = La vie de Saint Louis: le témoignage de Jehan, seigneur de Joinville. Texte du XIVe siècle. Ed. par Noel L. Corbett 1977. Sherbrooke, Québec: Naaman.

Queneau, Zazie = Queneau, Raymond: Zazie dans le métro. Paris: Gallimard.

\section{References}

Andersen, Henning (1973): Abductive and deductive change. In: Language 49, 765-93. Battye, Adrian / Roberts, Ian G. (1995): Introduction. In: Battye, Adrian / Roberts, Ian (eds.): Clause Structure and Language Change. Oxford: Oxford University Press, 3-28.

Blank, Andreas (1997): Prinzipien des lexikalischen Bedeutungswandels am Beispiel der romanischen Sprachen. Tübingen: Niemeyer.

Blank, Andreas (1999): Why do new meanings occur? A cognitive typology of the motivations for lexical change. In: Koch, Peter / Blank, Andreas (eds.): Historical Semantics and Cognition. Berlin, New York: Mouton de Gruyter, 61-89.

Bossong, Georg (1984): Diachronie und Pragmatik der spanischen Wortstellung. In: Zeitschrift für Romanische Philologie 100, 92-111.

Bühler, Karl (1982 [1934]): Sprachtheorie: die Darstellungsfunktion der Sprache. Stuttgart: G. Fischer. 
Chaudenson, Robert (1992): Des îles, des hommes, des langues: Essai sur la créolisation linguistique et culturelle. Paris: L'Harmattan.

Croft, William (1993): The Role of Domains in the Interpretation of Metaphors and Metonymies. In: Cognitive Linguistics 4, 335-70.

Croft, William (2000): Explaining language change: An evolutionary approach. London: Longman.

Dahl, Östen (1998): Grammaticalization and the life-cycle of constructions. Keynote lecture at the 17th Scandinavian Conference of Linguistics, August 20-22, 1998.

Detges, Ulrich (1999): Wie entsteht Grammatik? Kognitive und pragmatische Grundlagen der Grammatikalisierung von Tempusmorphemen. In: Lang, Jürgen/Neumann-Holzschuh. Ingrid (Hgg.): Reanalyse und Grammatikalisierung in romanischen Sprachen. Tübingen: Niemeyer, $31-52$.

Detges, Ulrich (2000): Two types of restructuring in French Creoles. In: Schneider. Edgar/Neumann-Holzschuh, Ingrid (eds.): Degrees of Restructuring in Creole Languages. Proceedings of the International Symposium, 24-27 June 1998. Amsterdam: Benjamins, 135-62.

Dowty, David (1991): Thematic proto-roles and argument selection. In: Language 67. 547-619.

Ducrot, Oswald (1980): Texte et énonciation. In: Bourcier, Danièle / Ducrot. Oswald (eds.): Les mots du discours. Paris: Minuit, 7-56.

Ernst, Gerhard (1985): Gesprochenes Französisch zu Beginn des 17. Jahrhunderts: direkte Rede in Jean Héroards "Histoire particulière de Louis XIII" (1605-1610). Tübingen: Niemeyer.

Gamillscheg, Ernst (1957): Historische Französische Syntax. Tübingen: Niemeyer.

Gévaudan, Paul (1999): Semantische Relationen in nominalen und adjektivischen Kompositionen und Syntagmen. In: Phin 9, 11-34. [http://www.phin de]

Givón, Talmy (1976): Topic, pronoun, and grammatical agreement. In: Li. Charles N. (ed.): Subject and Topic. New York: Academic Press, 149-88.

Givón. Talmy (1979): On Understanding Grammar. New York: Academic Press.

Godefroy, Frédéric. Dictionnaire de l'ancienne langue française. Paris 1891-1902.

Grice, H.P. (1975): Logic and conversation. In: Cole, Peter/Morgan, Jerry L. (eds.): Speech Acts. New York: Academic Press, 41-58.

Haas, Joseph (1916): Französische Syntax. Halle: Niemeyer.

Haase, Albert ( ${ }^{5} 1965$ [1889]): Syntaxe française du XVII siècle. München: Hueber.

Haiman, John (1994): Ritualization and the Development of Language. In: Pagliuca, William (ed.): Perspectives on Grammaticalization. Amsterdam: Benjamins, 3-28.

Harnisch, Rüdiger (1999): Morphosemantische Remotivation verdunkelter Komposita. Talk given at 21 th DGrS Annual Meeting, University of Konstanz, 1999/02/26.

Harris, Alice C./Campbell, Lyle (1995): Historical Syntax in cross-linguistic Perspective. Cambridge: Cambridge University Press.

Harris, Martin (1978): The Evolution of French Syntax: a Comparative Approach. London: Longman.

Haspelmath, Martin (1998): Does Grammaticalization need Reanalysis? In: Studies in Language 22, 315-51.

Haspelmath, Martin (1999): Why is Grammaticalization irreversible? In: Linguistics 37 , 1043-68.

Heine, Bernd/Reh, Mechthild (1984): Grammaticalization and Reanalysis in African Languages. Hamburg: Buske.

Heine, Bernd/Claudi, Ulrike/Hünnemeyer, Friederike (1991): Grammaticalization: A Conceptual Framework. Chicago: The University of Chicago Press.

Hopper, Paul (1991): On Some Principles of Grammaticization. In: Traugott, Elizabeth C./Heine, Bernd (eds.): Approaches to Grammaticalization. Vol. 1: Focus on Theoretical and Methodological Issues. Amsterdam: Benjamins, 17-35. 
Hopper, Paul. J./Elizabeth Closs Traugott (1993): Grammaticalization. Cambridge: Cambridge University Press.

Israel. Michael (1998): The Rhetoric of Grammar. Scalar Reasoning and Polarity Sensitivity. University of California, Doctoral dissertation, Ms.

Jakobson, Roman (1981): Linguistics and Poetics. In: Jakobson, Roman: Selected writings. Vol. III: Poetry of Grammar and Grammar of Poetry. The Hague: Mouton, 18-51.

Jensen. Frede (1990): Old French and Comparative Gallo-Romance Syntax. Tübingen: Niemeyer.

Keller. Rudi (1990): Sprachwandel. Von der unsichtbaren Hand in der Sprache. Tübingen: Francke (Translation: Language change: The invisible hand in language. London: Routledge 1994).

Koch. Peter (1999): Frames and contiguity. On the cognitive bases of metonymy and certain types of word formation. In: Panther, Klaus-Uwe/Radden, Günter (eds.): Metonymy in language and thought. Amsterdam: Benjamins, 233-53.

Koch. Peter (forthcoming): "Il ne me faut plus nule rien." - Changement sémantique, métataxe et réanalyse. In: Syntaxe et sémantique.

Koch. Peter/Oesterreicher, Wulf (1996): Sprachwandel und expressive Mūndlichkeit. In: Zeitschrift für Literaturwissenschaft und Linguistik 102, 64-96.

Krefeld, Thomas (1997): Dame phonétique, dame sémantique et les autres. Bemerkungen zur bündnerromanischen Negation. In: Holtus, Günter/Kramer, Johannes/Schweikkard, Wolfgang (eds.): Italica et Romanica. Festschrift für Max Pfister zum 65. Geburtstag. Vol. 1. Tübingen: Niemeyer: 24-9.

Langacker, Ronald W. (1977): Syntactic reanalysis. In: Li, Charles N. (ed.): Mechanisms of syntactic change. Austin: University of Texas Press, 57-139.

Langacker, Ronald W. (1987): Foundations of Cognitive Grammar. Vol. 1: Theoretical prerequisites. Stanford: Stanford University Press.

Lapesa, Rafael (2000): Estudios de moríosintaxis histórica del español. Madrid: Gredos.

Laury, Ritva (1997): Demonstratives in Interaction. The Emergence of a Definite Article in Finnish. Amsterdam: Benjamins.

Lehmann, Christian (1985): Grammaticalization: Synchronic Variation and Diachronic Change. In: Lingua e Stile 20, 303-18.

Lehmann, Christian (1989): Grammatikalisierung und Lexikalisierung. In: Zeitschrift für Phonetik, Sprachwissenschaft und Kommunikationsforschung 42, 11-9.

Lehmann, Christian (1993): Theoretical Implications of Grammaticalization Phenomena. In: Foley, William (ed.): The Role of Theory in Language Description. Berlin/New York: De Gruyter, 315-340.

Lehmann, Christian (1995a [1982]): Thoughts on Grammaticalization. München: Lincom.

Lehmann, Christian (1995b): Synsemantika. In: Jacobs, Joachim et al. (eds.): Syntax. Ein internationales Handbuch zeitgenössischer Forschung. Vol. 2. Berlin/New York: de Gruyter, $1251-66$.

Lehmann, Christian (1999) New Reflections on Grammaticalization and Lexicalization. Talk given at Symposium New Reflections on Grammaticalization, University of Potsdam, 1999/06/17.

Lightfoot, David (1979): Principles of Diachronic Syntax. Cambridge: Cambridge University Press.

Mair, Walter (1992): Expressivität und Sprachwandel: Untersuchungen zur Rolle der Subjektivität in der Entwicklung der romanischen Sprachen. Frankfurt a. M. et a.: Lang.

Marchello-Nizia, Christiane (1979): Histoire de la langue française aux XIVe et XVe siècles. Paris: Bordas. 
Martin, Robert (1972): La 'négation de virtualité' du moyen français. In: Romania 93, 20-49.

Mayerthaler, Willi (1977): Studien zur theoretischen und französischen Morphologie. Tübingen: Niemeyer.

Mayerthaler, Willi (1981): Morphologische Natürlichkeit. Wiesbaden: Athenaion.

Möhren. Frankwalt (1980): Le renforcement affectif de la négation par l'expression d'une valeur minimale en ancien français. Tübingen: Niemeyer.

Nunberg, Geoffrey D. (1979): The Non-uniqueness of Semantic Solutions: Polysemy. In: Linguistics and Philosophy 3,143-84.

Nyrop, Kristoffer (1930): Grammaire historique de la langue française. Vol.6. Kopenhagen: Gyldendalske boghandel, Nordisk Forlag.

Offord, Malcolm (1976): Negation in 'Berinus': A contribution to the study of negation in fourteenth century French. In: Zeitschrift für romanische Philologie 97, 313-385.

Price, Glanville (1971): The French Language: Present and Past. London: Arnold.

Robert Electronique $=$ Le Robert Electronique. Outil d'aide à la rédaction sur la base du Grand Robert de la langue française. Paris 1994.

Roberts, Ian (1993a): Verbs and Diachronic Syntax. A Comparative History of English and French. Dordrecht: Kluwer.

Roberts, Ian (1993b): A formal account of grammaticalization in the history of Romance futures. In: Folia Linguistica Historica 13, 219-58.

Schrodt, Richard (1993): Von der Diskurssyntax zur Satzsyntax: Reanalyse und/oder Grammatikalisierung in der Geschichte der deutschen Nebensätze. In: Folia Linguistica Historica 13, $259-78$.

Schwegler. Armin (1988): Word-order changes in predicate negation strategies in Romance languages. In: Diachronica 5, $21-58$.

Schwegler, Armin (1990): Analyticity and Syntheticity. A Diachronic Perspective with Special Reference to Romance Languages. Berlin/New York: Mouton de Gruyter.

Schwenter, Scott A. (1994): Hot news and the grammaticalization of perfects. In: Linguistics 32, $995-1028$.

Thomas, Earl W. (1969) The Syntax of Spoken Brazilian Portuguese. Nashville: Vanderbilt University Press.

Timberlake, Alan (1977): Reanalysis and actualization in syntactic change. In: Li, Charles N. (ed.): Mechanisms of syntactic change. Austin: University of Texas Press, $141-77$.

Tobler $=$ Tobler-Lommatzsch (1925): Altranzösisches Wörterbuch. 10 vols. Stuttgart: Franz Steiner Verlag Wiesbaden.

Traugott, Elizabeth Closs/König, Ekkehard (1991): The semantics-pragmatics of grammaticalization revisited. In: Traugott, Elizabeth C./König, Ekkehard (eds.): Approaches to Grammaticalization, vol. I: Focus on Theoretical and Methodological Issues. Amsterdam: Benjamins, 189-218.

Traugott, Elizabeth Closs (1995): Subjectification in grammaticalization. In: Stein. Dieter/Wright, Susan (eds.): Subjectivity and subjectivisation. Linguistic perspectives. Cambridge: Cambridge University Press, $31-54$.

van Kemenade, Ans/Vincent, Nigel (1997): Introduction: Parameters and Morphosyntactic Change. In: van Kemenade. Ans / Vincent, Nigel (eds.): Parameters of Morphosyntactic Change. Cambridge: Cambridge University Press 1997, 1 - 25.

Vennemann, Theo (1974): Topics, Subjects and Word Order: from SXV to SVX via TVX. In: Anderson, John M./Jones, Charles (eds.): Historical Linguistics I. Syntax, Morphology internal and comparative reconstruction. Proceedings of the First International Conference on Historical Linguistics, Edinburgh, 2nd-7th September 1973. Amsterdam: North-Holland Publishing Company, 339-76. 
Waltereit, Richard (1999): Reanalyse als metonymischer Prozeß. In: Lang, Jürgen/ Neumann-Holzschuh, Ingrid (eds.): Reanalyse und Grammatikalisierung in romanischen Sprachen. Tübingen: Niemeyer. 19-29.

Wartburg. Walther von (1922): Französisches etymologisches Wörterbuch. 25 vols. Bonn: Klopp.

Wartburg. Walther von $\left({ }^{10} 1971\right.$ [1934]): Évolution et structure de la langue française. Bern: Francke.

Winters. Margaret E. (1987): Innovations in French Negation. In: Diachronica 4, $27-52$. Zingarelli = Il Nuovo Zingarelli. Vocabolario della lingua italiana ':1993. Bologna: Zanichelli.

Eingereicht: 1.7 .2001

Überarbeitete Fassung eingereicht: 21.12.01

Ulrich Derges und Richard Wahtereit, Universität Tübingen, Romanisches Seminar, Wilhelmstr. 50, 72074 Tübingen 